\title{
Experimental Analysis of Slip Systems Activation in Neutron-Irradiated Zirconium Alloys and Comparison with Polycrystalline Model Simulations
}

\author{
F. ONIMUS, J.L. BÉCHADE, and D. GILBON
}

\begin{abstract}
The deformation mechanisms of recrystallized zirconium alloys are strongly influenced by neutron irradiation with significant consequences on the mechanical behavior at the macroscopic scale. It is especially observed, through transmission electron microscopy, that the dislocation channeling process in the basal plane is the main deformation mechanism after irradiation. A polycrystalline modeling which takes into account both the specific post-irradiation deformation mechanisms, and the texture of the material has been developed. This physically based model reproduces the mechanical behavior of the material for both monotonic and cyclic tests. The slip system activities have been computed for several grains observed by TEM. The activation of the basal slip is very well predicted. Moreover, the activation of $\langle c+a\rangle-$ pyramidal slip observed only in few grains, and the absence of prismatic activation is also well predicted showing the reliability of the modeling.
\end{abstract}

DOI: $10.1007 / \mathrm{s} 11661-012-1463-3$

(c) The Minerals, Metals \& Materials Society and ASM International 2012

\section{INTRODUCTION}

ZIRCONIUM alloys are widely used in the nuclear industry as structural material for the fuel assembly and as cladding tubes for the fuel of pressurized water reactor (PWR). As the cladding tube is the first barrier against the dissemination of radioactive elements, it is of prime importance to have a good knowledge and ability to predict the effect of neutron irradiation on the mechanical behavior of the material. At the macroscopic scale, the effect of neutron irradiation is well characterized using conventional mechanical tests. It is established that irradiation leads to a strong hardening (increase of the yield stress as well as ultimate tensile strength) and to a significant decrease of the uniform elongation.

However, in order to have a good prediction of the effect of irradiation on the mechanical behavior of zirconium alloys, by means of a physically based polycrystalline model, a good knowledge and understanding of the deformation mechanisms is required.

Un-irradiated zirconium alloys, with hexagonal closed packed (HCP) structure, are known to deform mainly by the glide of dislocations on the $\{10 \overline{1} 0\}$ firstorder prismatic slip planes along the $\langle 11 \overline{2} 0\rangle$ glide direction of the HCP lattice. ${ }^{[1,2]}$ Especially for the recrystallized zirconium alloys as cold-rolled strips or tube deformed up to 4 pct plastic strain at $623 \mathrm{~K}$ $\left(350{ }^{\circ} \mathrm{C}\right)$, it has been demonstrated that the plastic

F. ONIMUS, and J.L. BÉCHADE, Researchers, are with the Service de Recherches Métallurgiques Appliquées, CEA-Saclay, Gifsur-Yvette 91191, France. Contact e-mail: fabien.onimus@cea.fr D. GILBON, Researcher, is with the Département des Materiaux pour le Nucléaire, CEA-Saclay, Gif-sur-Yvette 91191, France.

Manuscript submitted April 6, 2012.

Article published online October 17, 2012 deformation occurs mainly by prismatic slip. ${ }^{[3,4]}$ The basal $\{0001\}$ and the first-order pyramidal $\{10 \overline{1} 1\}$ slip systems with $\langle\mathrm{a}\rangle$ Burgers vectors are also known to operate. Furthermore, as reviewed by Tenckhoff, ${ }^{[2]}$ numerous evidences for $\langle\mathrm{c}+\mathrm{a}\rangle$ slip activation are reported in the literature. Indeed, first-order pyramidal $\{10 \overline{1} 1\}$ slip along the $\langle\mathrm{c}+\mathrm{a}\rangle$ direction is a hard slip system, but it is the only one which allows the accommodation of the plastic strain along the $\langle c\rangle$ direction. Twinning can also occur, at lower temperature, to accommodate the strain in the $\langle\mathrm{c}\rangle$ direction.

Neutron irradiation induces a high density of small point defect clusters in the form of $\langle a\rangle$-type dislocation loops. ${ }^{[5-8]}$ This high defect density has a strong impact on the microscopic deformation mechanisms and therefore on the mechanical properties of the material. Indeed, they act as obstacles against dislocation glide leading to the strong hardening observed at the macroscopic scale. Nevertheless, these obstacles can be overcome by dislocations when a sufficient stress is applied, the loops being subsequently annihilated or dragged by dislocations following various possible mechanisms. ${ }^{[9,10]}$ Then, this leads to the clearing of loops and the creation of a zone free of defects, where further dislocations are able to glide freely. The so-called dislocation channeling mechanism has been observed in various irradiated metals and alloys, as reviewed by Wechsler ${ }^{[11]}$ and Luft. $^{[12]}$ In the case of zirconium alloys, several authors have reported defect-free channels ${ }^{[13-19]}$ Recently, an extensive study ${ }^{[9,20]}$ of this phenomenon has been conducted on neutron-irradiated recrystallized zirconium alloys tested at $623 \mathrm{~K}\left(350^{\circ} \mathrm{C}\right)$. It has been established that for neutron-irradiated material strained during tensile test performed in the transverse direction or an internal pressure (IP) test on cladding tube, channels are parallel to the basal plane and are well 
explained in terms of basal slip. This has to be compared to the un-irradiated $\mathrm{Zr}$ alloys where prismatic glide is mainly activated. The modification of easy glide slip system is believed to be due to differences in elementary interactions between dislocation and loops as discussed in References 9 and 10.

Based on this thorough experimental study, an original polycrystalline model has been developed for neutron-irradiated recrystallized zirconium alloys. ${ }^{[21]}$ This new model takes into account both the polycrystalline nature of the material and the specific deformation mechanism:the dislocation channeling phenomenon in the basal plane. This model has been fitted to monotonic tests performed with a transverse and IP loading conditions (biaxial test with $\sigma_{\mathrm{zz}}=\sigma_{\theta \theta} / 2$ ) and validated on cyclic loading tests performed in the transverse direction. Furthermore, at the microscopic scale the overall basal slip system activities were in reasonable agreement with the observation of basal channeling. However, the detailed slip system activity for each grain studied was not compared with transmission electron microscope (TEM) observations in this first study. Furthermore, no information was available concerning the activation of pyramidal $\langle c+a\rangle$ slip system.

In this article, in order to improve the polycrystalline model at the microscopic scale, TEM observations have been performed on neutron-irradiated specimens tested in transverse tensile (TT) tests and IP tests at $623 \mathrm{~K}$ $\left(350{ }^{\circ} \mathrm{C}\right)$. For each grain, the orientation with respect to the macroscopic loading has been measured. In each of these grains the presence of basal or prismatic channels has been systematically studied as well as the presence of $\langle\mathrm{c}+\mathrm{a}\rangle$ dislocations. The orientations of the studied grains have then been introduced into the polycrystalline model, thanks to a specific procedure, and the computed slip system activities for each grain have been compared with TEM observations.

First, the materials and the experimental techniques are described. Then, in the second section of this article, the TEM observations of basal dislocation channels at high magnification and at low magnification are given, as well as some observations of $\langle c+a\rangle$ dislocations. Finally, the polycrystalline model is described, and simulations are compared with TEM observations.

\section{MATERIALS AND EXPERIMENTAL DETAILS}

For this experimental study, thin foils were taken out of two samples. The sample \#1 (referred as B in Reference 9) was made of fully recrystallized Zircaloy-4 (Zy-4), and the sample \#2 (referred as C in Reference 9) was made of fully recrystallized $\mathrm{Zr}-1$ pctNb-O as tested in Reference 22. The chemical compositions of the two alloys are given in Table I.

The tensile test specimen \#1 was taken from a $10 \mathrm{~mm}$ thick plate which exhibited the usual texture of recrystallized $\mathrm{Zr}$ alloys cold rolled sheet or cladding tube (Figure 1). The tensile test specimen was machined out in the TD-ND plane (Transverse Direction-Normal Direction) with the tensile direction parallel to the

Table I. Alloys Chemical Compositions (in wt pet)

\begin{tabular}{llllllrr}
\hline Specimen & Materials & $\mathrm{Sn}$ & $\mathrm{Fe}$ & $\mathrm{Cr}$ & $\mathrm{Nb}$ & $\mathrm{O}$ & $\mathrm{Zr}$ \\
\hline$\# 1$ & $\mathrm{Zy}-4$ & 1.40 & 0.2 & 0.105 & - & 0.125 \\
$\# 2$ & $\mathrm{Zr}-1$ pct Nb-O & - & - & - & 1.0 & 0.125 \\
\hline
\end{tabular}

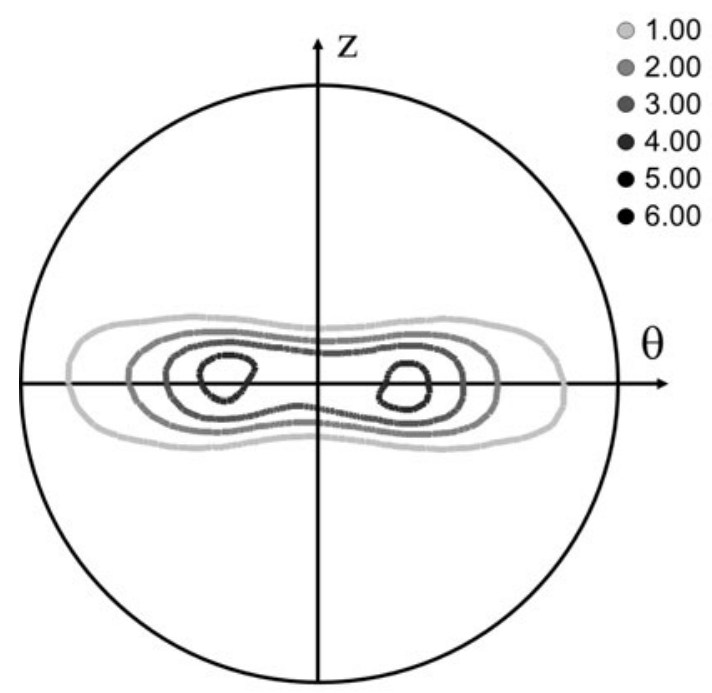

(a) $\{0002\}$ pole figure

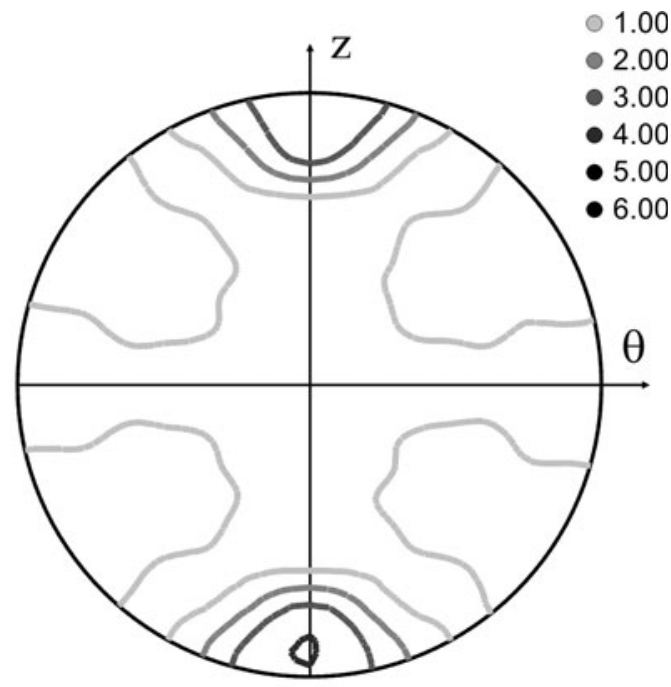

(b) $\{11 \overline{2} 0\}$ pole figure

Fig. 1-Typical (a) (0002) and $(b)\{11 \overline{2} 0\}$ pole figures of the recrystallized zirconium alloy tube measured by standard X-ray diffraction texture analysis. 
transverse direction (TD). This specimen was then irradiated in the experimental reactor Siloe at $553 \mathrm{~K}$ $\left(280{ }^{\circ} \mathrm{C}\right)$ up to $0.6 \times 10^{25} \mathrm{~nm}^{-2}$. On this neutronirradiated specimen, a tensile test was performed at $623 \mathrm{~K}\left(350^{\circ} \mathrm{C}\right)$ with a strain rate of $1.6 \times 10^{-4} \mathrm{~s}^{-1}$. The test was conducted until failure. Two thin foils were taken in the gauge of the specimen far from the necking zone. According to the stress-strain curve, the recorded uniform elongation was 0.36 pct. The thin foils were mechanically polished in hot cell and electro-polished in gloves box.

The specimen \#2 was machined out of a cladding tube, in the form of a $120-\mathrm{mm}$-long tube, irradiated in a commercial PWR at $623 \mathrm{~K}\left(350^{\circ} \mathrm{C}\right)$ up to a fluence of $12 \times 10^{25} \mathrm{~nm}^{-2}$. The specimen exhibited the usual texture of recrystallized $\mathrm{Zr}$ alloys cladding tube (Figure 1). This tube was then sealed at one end by means of a cold crimped Swagelock and linked to a high pressure system at the other end to perform a closed end burst test. The test was conducted at $623 \mathrm{~K}\left(350{ }^{\circ} \mathrm{C}\right)$ with a strain rate of $3 \times 10^{-4} \mathrm{~s}^{-1}$ until failure. Two thin foils were taken from the homogeneously plastically deformed zone $\left(\varepsilon^{\mathrm{p}}=0.5 \mathrm{pct}\right)$ as measured by a laser imaging technique. The tests conditions are recalled in Table II.

TEM analyses have been performed using conventional imaging and diffraction techniques on a $300 \mathrm{kV}$ high-voltage TEM. The grains were first observed at low magnification, and the crystallographic orientations were determined by indexing diffraction pattern. The stereographic projections of the grains were then drawn and the Euler's angles measured.

The method used to study basal channels and $\langle\mathrm{c}+\mathrm{a}\rangle$ dislocations consists in tilting the grain to have the electron beam $(\underline{B})$ close to the zone axis $\underline{B} \approx\langle 11 \overline{2} 0\rangle$ (or close to zone axis $\underline{B} \approx\langle 10 \overline{1} 0\rangle)$. The $\langle\mathrm{c}+\overline{\mathrm{a}}\rangle$ dislocations are easily observed using the diffraction vector $g=0002$, when all the crystalline defects with $\langle a\rangle$ Burgers vector are invisible. Then, by tilting on the same area the grain such that $g \neq 0002$, all the $\langle a\rangle$ loops become visible. Consequently, the basal channels appear as white clear bands within the gray matrix full of $\langle a\rangle$ loops, the contrast between channel and matrix being maximum in these conditions. Furthermore, the trace of the basal channel is nearly normal to the [0002] direction seen on the diffraction pattern.

In addition to these TEM observations performed at low magnification, the widest channel has been investigated at high magnification. The microstructures inside this channel, such as dislocations and remaining loops, were observed using conventional imaging technique.
Owing to the strong texture of the cladding tube, the observation of basal dislocation channels and $\langle c+a\rangle$ dislocations in the sample \#2 required large tilting angles. Owing to the tilt limitation of the double tilt specimen holder $( \pm 45 \mathrm{deg})$, only a limited number of grains have been investigated in this sample. By contrast, owing to the strong texture of the sheet (specimen $\# 1)$, the $\langle c\rangle$ axis of the majority of the grain is contained in the plane of the thin foil, allowing an easy observation of basal channels and $\langle\mathrm{c}+\mathrm{a}\rangle$ dislocations. In addition to the thorough study of basal channels and $\langle\mathrm{c}+\mathrm{a}\rangle$ dislocations, the presence, or the absence, of prismatic channel has also been recorded.

It is worth noting that owing to the very high density of small $\langle a\rangle$ loops, $\langle a\rangle$ line dislocations cannot be observed. Indeed, as they have the same Burgers vector, extinction technique cannot be applied. Only clear bands, the evidence of dislocation glide, can be experimentally observed by TEM. As it is considered that most of the plastic strain occurs by dislocation channeling mechanism, the TEM investigation is able to estimate the main source of plastic strain. However, it is also possible that limited plastic strain occurs by dislocation glide without clearing of loops.

\section{A. Transverse Tensile Tests Specimen (Specimen \#1)}

After TT tests performed at $623 \mathrm{~K}\left(350{ }^{\circ} \mathrm{C}\right)$ the presence or the absence of basal channels has been studied in 10 different grains by TEM. The orientation of each studied grain in specimen \#1 is shown on a (0002) pole figure in Figure 13. Each grain is indicated by its number. For 6 grains, basal channeling has been observed. Pictures at low magnification of 4 grains containing basal channels are shown Figures 2 and 5. The presence or The absence of basal channels is plotted Figure 14 for each studied grain in the form of a (0002) pole figure. When no basal channel is observed an empty circle is drawn. When basal channels are observed, a filled triangle is plotted. For easier reading, the pole figure is shown in a frame with the transverse direction (TD referred as $\theta$ direction on the plot) as $x$ axis and rolling direction (RD referred as $z$ direction on the plot) as $y$ axis, although the thin foils are observed in the NDTD plane. This change of frame is obtained by a rotation of $90 \mathrm{deg}$ around the TD direction. On this (0002) pole figure, the maximum basal Schmid factor is also shown in gray scale for 240 different orientations. This allows a direct comparison between the occurrence of basal slip in the studied grains and the basal Schmid factors for these grains. As it is not known which basal

Table II. Specimens, Irradiation, and Test Conditions

\begin{tabular}{|c|c|c|c|c|c|c|c|}
\hline Specimen & Materials & $\begin{array}{l}\text { Fluence } \\
\left(\mathrm{nm}^{-2}\right)\end{array}$ & $\begin{array}{l}\text { Irradiation } \\
\text { Temperature }\end{array}$ & $\begin{array}{c}\text { Mechanical } \\
\text { Test }\end{array}$ & $\begin{array}{c}\text { Test } \\
\text { Temperature }\end{array}$ & $\begin{array}{c}\text { Strain } \\
\text { Rate }\left(\mathrm{s}^{-1}\right)\end{array}$ & $\begin{array}{c}\text { Plastic } \\
\text { Strain (pct) }\end{array}$ \\
\hline$\# 1$ & $\mathrm{Zy}-4$ & $0.6 \times 10^{25}$ & $553 \mathrm{~K}$ & $\begin{array}{l}\text { transverse tensile test } \\
\text { (specimen in } \\
\text { ND-TD plane) }\end{array}$ & $623 \mathrm{~K}$ & $1.6 \times 10^{-4}$ & 0.36 \\
\hline$\# 2$ & $\mathrm{Zr}-1$ pet $\mathrm{Nb}-\mathrm{O}$ & $12 \times 10^{25}$ & $623 \mathrm{~K}$ & closed end burst test & $623 \mathrm{~K}$ & $3 \times 10^{-4}$ & 0.5 \\
\hline
\end{tabular}




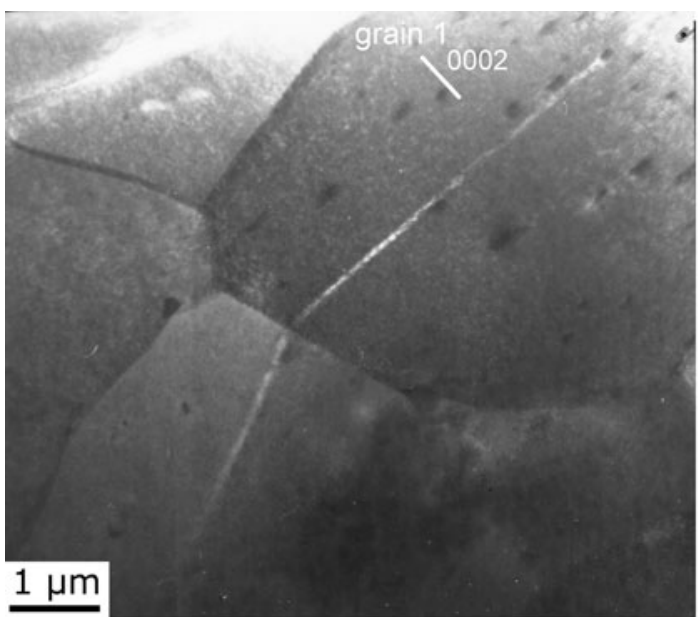

(a)

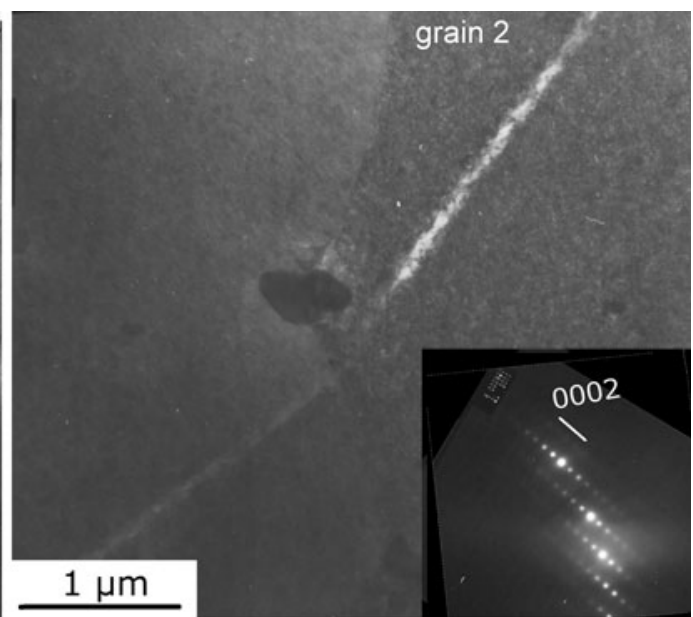

(b)

Fig. 2-Propagating basal channels observed in two-beam diffraction condition. The [0002] direction is indicated on the pictures. (a) grain 1 of specimen $\# 1$ is at the top of the picture, $(b)$ grain 2 of specimen \#1 is at the top of the picture.

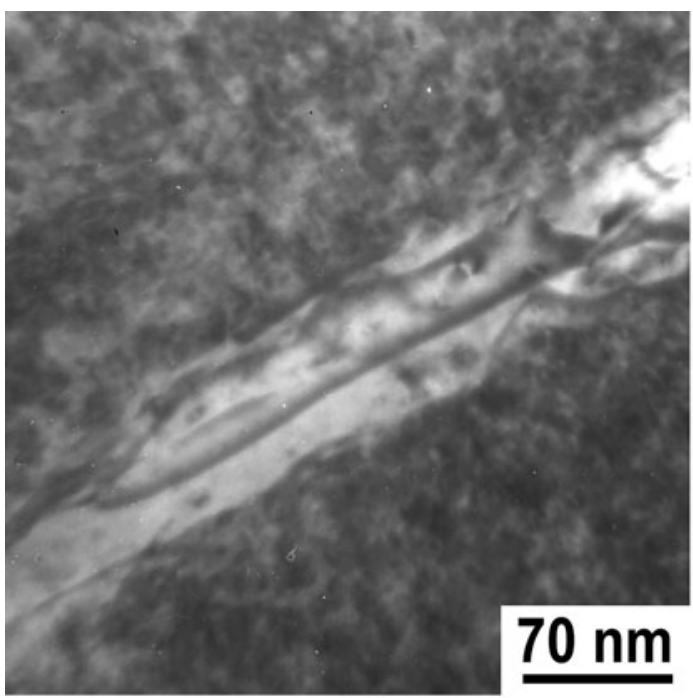

(a)

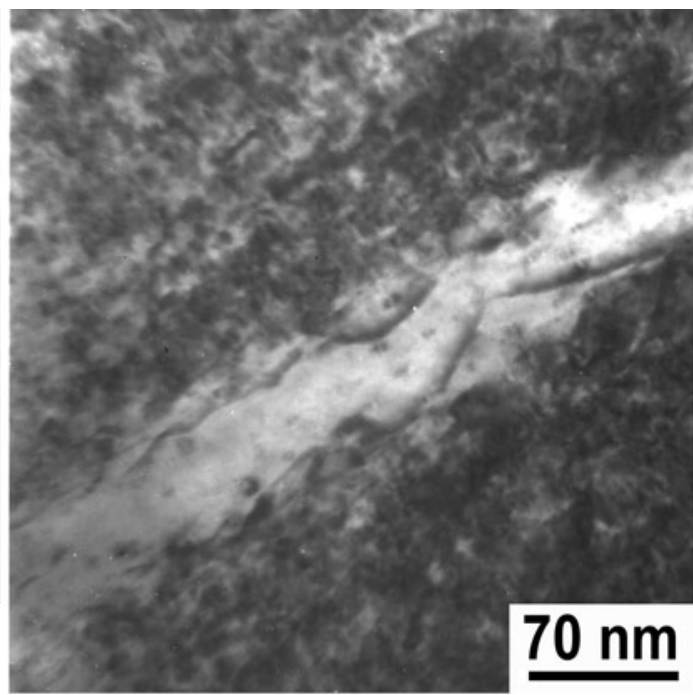

(b)

Fig. 3-Basal channel observed at high magnification in grain 2 of specimen \#1. Loops and long wavy dislocation can be observed inside the channel and at the channel wall.

slip system is activated, the maximum basal Schmid factor is computed here. From this (0002) pole figure, it can be noticed that a good correlation is obtained between the occurrence of basal slip and the basal Schmid factor. Indeed, it can be seen that basal slip occurs when the basal Schmid factor is higher than 0.3. These results are in good agreement with TEM observations reported in Reference 9 where 38 grains out of 81 grains studied contained basal channels, with a good correlation with Schmid factors.

Furthermore, in this specimen, propagation of basal channels from grain to grain is observed as shown on the grains 1 and 2 reported, respectively, in Figures 2(a) and (b). The channel in the grain 2 (Figure 2(b)) has been observed at high magnification (Figure 3). It can be noticed that the basal channel is nicely cleared and is nearly free of loops. Few remaining loops exhibiting the usual strain contrast can still be observed inside the channel. However, most remarkably, long and wavy dislocations are also observed within the basal channel. Burgers vector determination using different diffraction vectors is very difficult in that case as the dislocations can only be observed when the basal plane contains the electron beam. Assuming that the activated basal slip system has the highest basal Schmid factor (Burgers vector close to the maximum shear stress direction), it can be deduced from the stereographic projection of the grain given in Figure 4 that the dislocations observed have the La) Burgers vector framed in Figure 4 (the closest to the maximum shear direction), and are therefore mainly of 


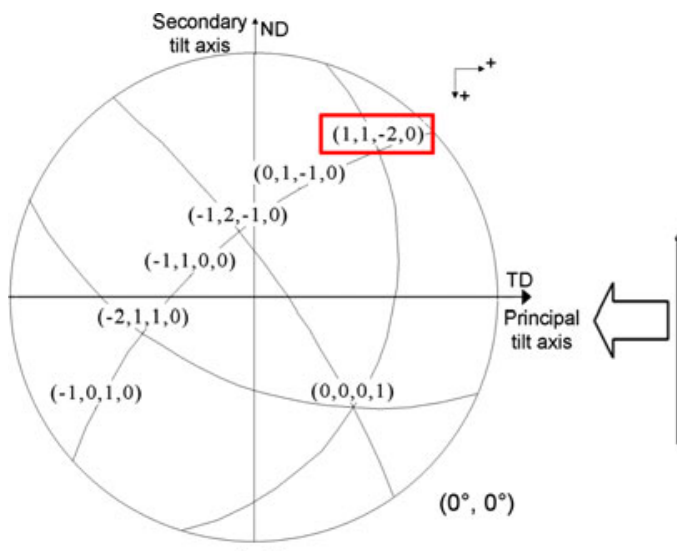

(a)

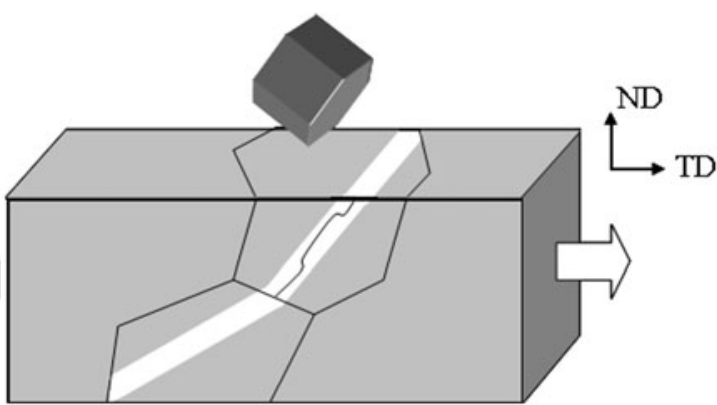

(b)

Fig. 4 - (a) Stereographic projection of the grain 2 of specimen \#1 corresponding to Fig. 2(b). (b) Schematic representation showing the propagation of channels and the $\langle a\rangle$ dislocations easily observed in the ND-TD plane.

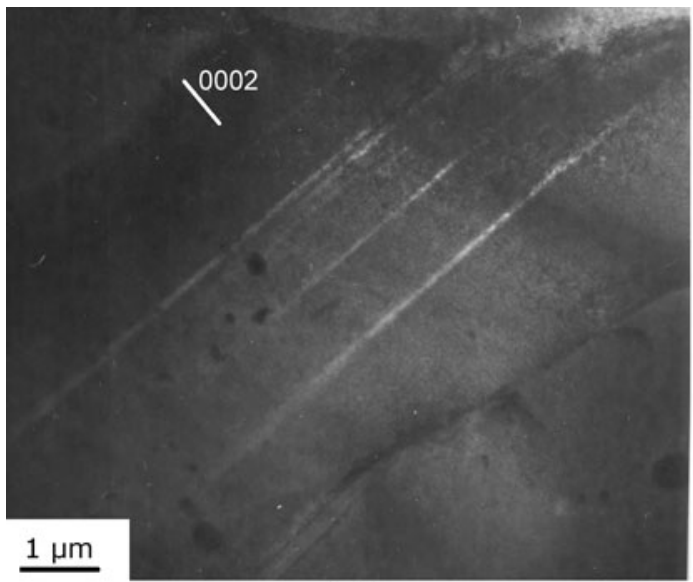

(a)

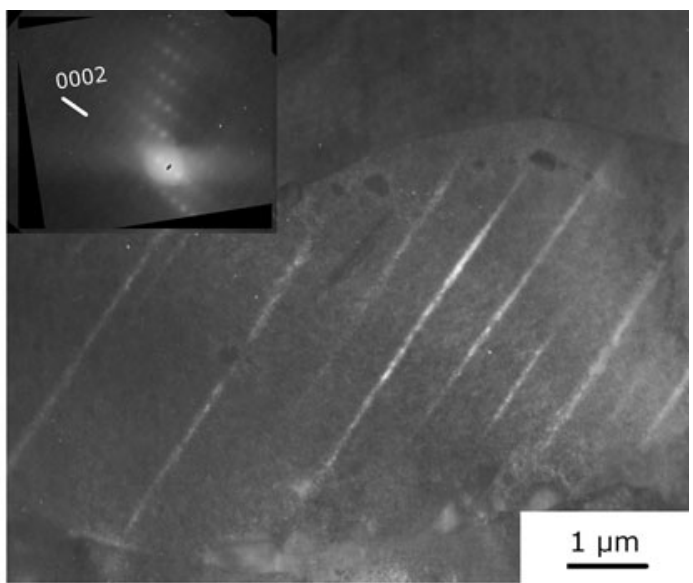

(b)

Fig. 5-Basal channels observed in two-beam condition $(a)$ in grain 4 and $(b)$ in grain 6 of specimen \#1. The [0002] direction is indicated on the pictures.

screw type. It has to be emphasized that these results are not deduced from proper Burgers vector analysis but assumed from the orientation of the observed dislocation and the orientation of the easy basal slip system. Other pictures of basal channels obtained at low magnification are shown in Figure 5.

In 6 grains, $\langle\mathrm{c}+\mathrm{a}\rangle$ dislocations have been looked for. $\mathrm{No}\langle\mathrm{c}+\mathrm{a}\rangle$ dislocation has been observed, despite the very well-suited orientation of the grains for their observation. The absence of $\langle\mathrm{c}+\mathrm{a}\rangle$ dislocation is indicated by empty red circle on a (0002) pole figure for each grain studied (Figure 15). On this pole figure, the maximum $\langle c+a\rangle-$ pyramidal Schmid factor for 240 orientations is also given in gray scale. Despite the high maximum $\langle c+a\rangle$-pyramidal Schmid factor computed for each of these grains, no $\langle\mathrm{c}+\mathrm{a}\rangle$ glide occurs, proving that the critical resolved shear stress of this slip system is higher than the one of basal plane. In addition to these results, it can be noticed that prismatic channel has never been observed in any of these grains, despite the relatively high prismatic Schmid factor of some of them (Figure 14), also proving the high critical resolved shear stress of this slip system after irradiation compared to the basal one.

\section{B. Internal Pressure Test Specimen (Specimen \#2)}

After IP test performed at $623 \mathrm{~K}\left(350{ }^{\circ} \mathrm{C}\right)$ the thin foils were observed by TEM. The orientation of the 18 grains studied for specimen \#2 are given in the (0002) pole figure and indicated by numbers in Figure 16. In these thin foils, basal channels were observed in 8 out of 16 grains. TEM pictures of 4 grains are shown from Figures 6 through 8 . The presence of basal channel is indicated as filled red triangle on the (0002) pole figure plotted in Figure 17. The absence of basal channel is indicated as empty red circle. The (0002) pole figure is shown in the $\theta$ (as $x$ axis) and $z$ (as $y$ axis) frames, corresponding to the plane of the thin foil. On this (0002) pole figure, the maximum basal Schmid factor is also shown in gray scale for 240 different orientations. However, as IP test induces a biaxial stress state $\left(\sigma_{\theta \theta} ; \sigma_{z z} \approx \sigma_{\theta \theta} / 2\right)$, the classical definition of the Schmid 


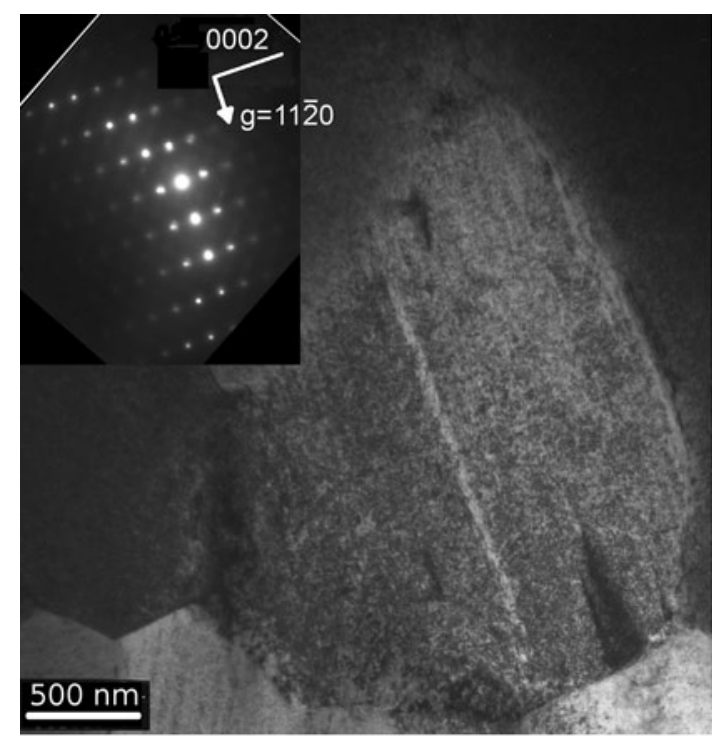

(a)

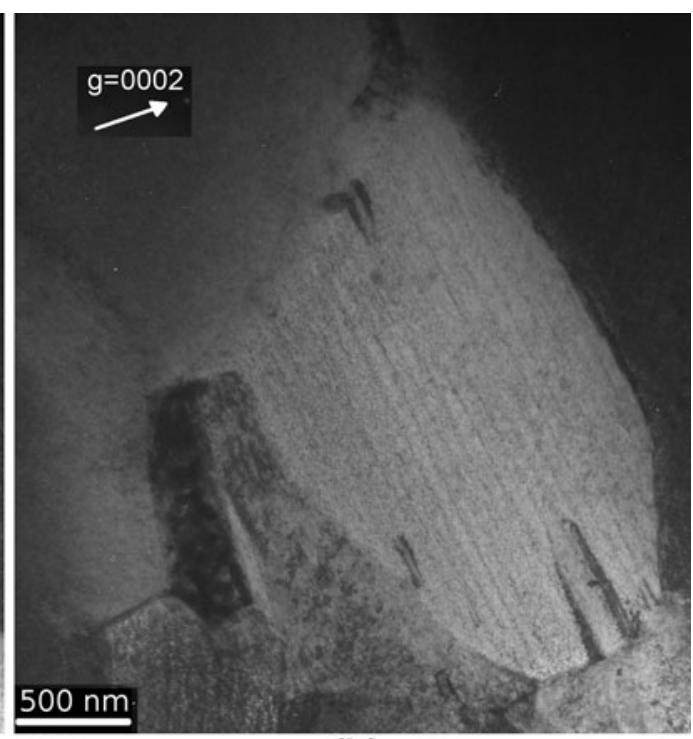

(b)

Fig. 6 - (a) Basal channels observed in grain 1 of specimen \#2 in two-beam condition, with diffraction vector $g=11 \overline{2} 0$ and close to the zone axis $\underline{B} \approx\langle 1010\rangle$. (b) Grain 5 of specimen $\# 2$ observed in two-beam condition, with diffraction vector $\underline{g}=0002$. No $\langle\mathrm{c}+\mathrm{a}\rangle$ dislocation is observed.

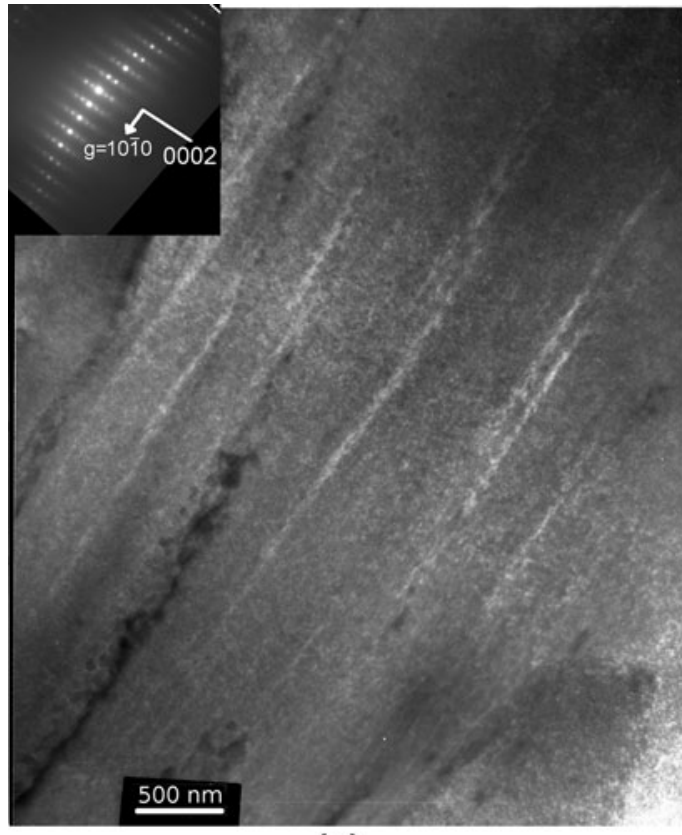

(a)

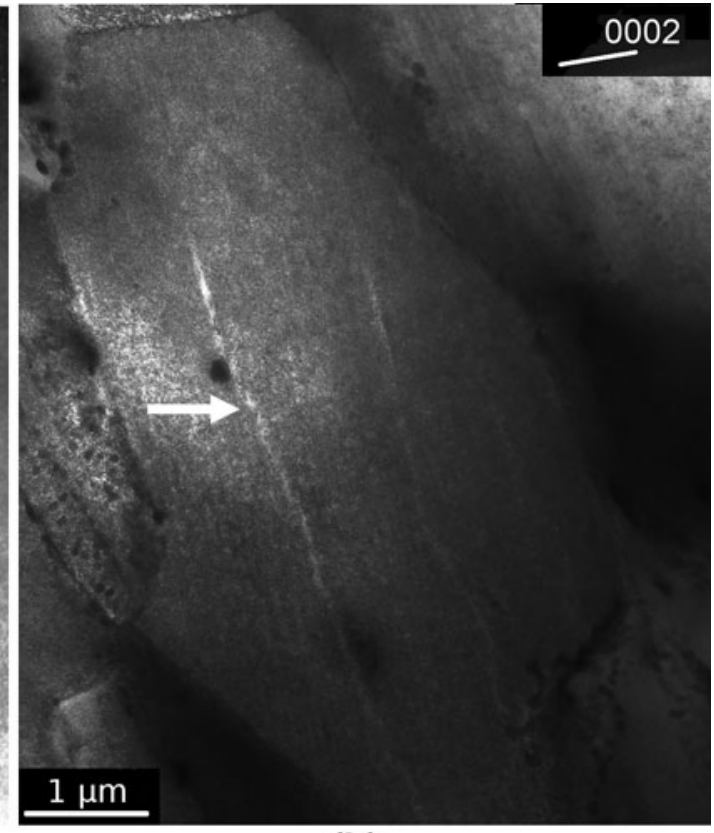

(b)

Fig. 7- (a) Basal channels observed in grain 3 of specimen \#2 in two-beam condition, with diffraction vector $g=10 \overline{1} 0$ and close to the zone axis $\underline{B} \approx\langle 1120\rangle$. (b) Basal channels, exhibiting cross-slip in the pyramidal plane (shown by a white arrow), observed in grain 12 of specimen \#2 in two-beam condition. The [0002] direction is indicated on the picture.

factor cannot be used. It has therefore been chosen, as proposed in Reference 9, to define the Schmid factor for a biaxial test as the resolved shear stress divided by the Tresca equivalent stress (twice the maximum shear stress associated with the biaxial stress state), which is equal to the hoop stress $\left(\sigma_{\theta \theta}\right)$ in our case. From the knowledge of the orientation of the normal of the slip plane $\left(\underline{n}_{s}\right)$ and the slip directions $\left(\mathrm{m}_{\mathrm{s}}\right)$ in the macroscopic frame, the resolved shear stress $\left(\tau_{\mathrm{s}}\right)$ is computed according to
Eq. [1]. The Schmid factor $F_{\mathrm{S}}$ is then deduced as Eq. [2]. This is practically done by means of the polycrystalline model described in the second section of this article.

$$
\tau_{\mathrm{s}}=\frac{1}{2} \underline{\underline{\sigma}}_{\mathrm{g}}:\left(\underline{\mathrm{n}}_{\mathrm{s}} \otimes \underline{\mathrm{m}}_{\mathrm{s}}+\underline{\mathrm{m}}_{\mathrm{s}} \otimes \underline{\mathrm{n}}_{\mathrm{s}}\right)
$$

where $\sigma_{g}$ is the stress tensor applied on the grain, which is equal to the macroscopic applied stress in that case. 


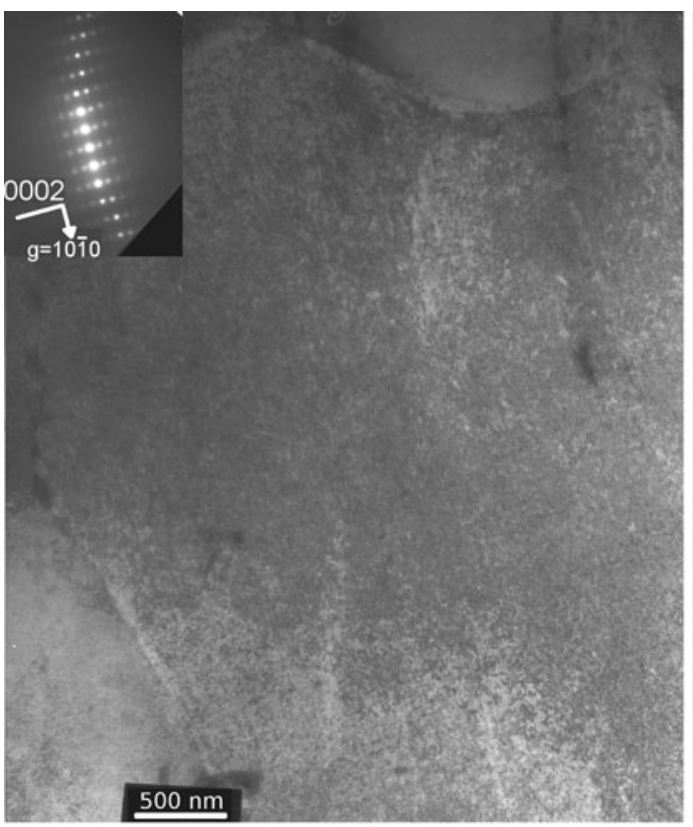

(a)

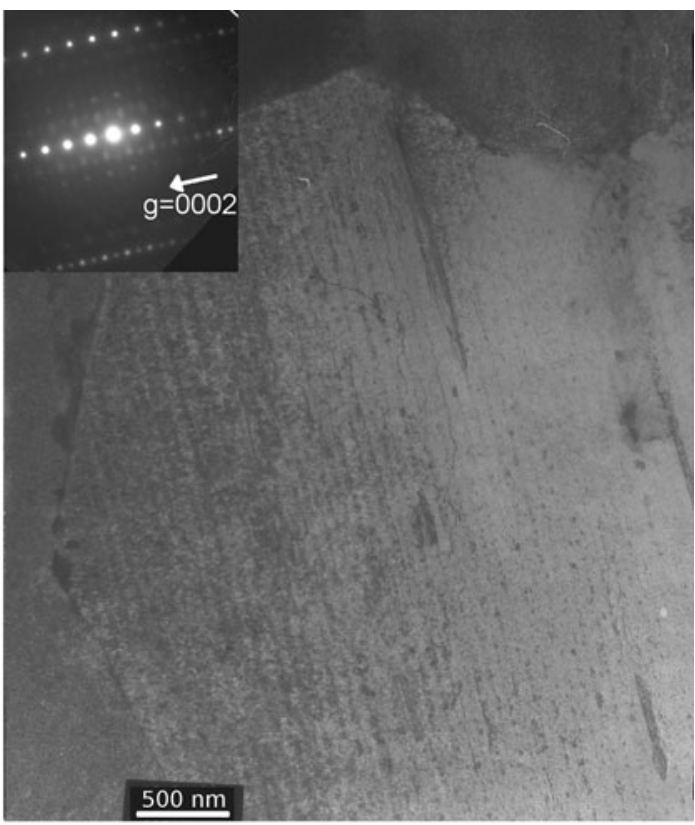

(b)

Fig. 8- (a) Grain 7 of specimen \#2 in two-beam condition with diffraction vector $g=10 \overline{1} 0$ and close to the zone axis $\underline{B} \approx\langle 11 \overline{2} 0\rangle$. No channel is observed. $(b)\langle c+a\rangle$ dislocations observed in grain 7 in two-beam condition, with diffraction vector $\underline{g}=0002$.

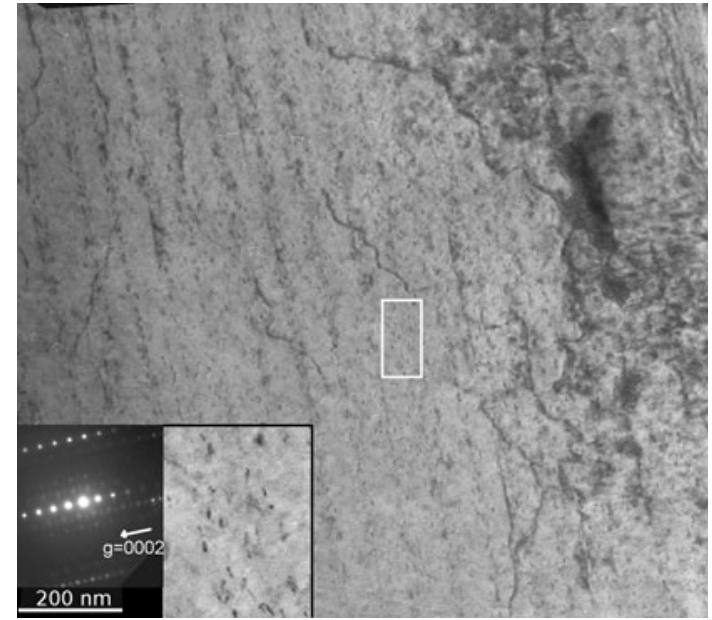

Fig. $9-\langle\mathrm{c}+\mathrm{a}\rangle$ dislocations observed at high magnification in grain 7 with $g=0002$ diffraction vector. $\beta$-Nb needles can also be observed on the picture. Encapsulated $\beta-\mathrm{Nb}$ needles are shown at higher magnification.

$$
F_{\mathrm{s}}=\frac{\tau_{\mathrm{s}}}{\sigma_{\theta \theta}}
$$

As for specimen \#1, a good correlation is obtained between the occurrence of basal slip and a high basal Schmid factor (Figure 17). Indeed, basal slip occurs mainly when the basal Schmid factor is higher than 0.3. In some grains, deviation of the channel in the pyramidal plane occurs, as shown Figure 7(b).
Moreover, in these thin foils $\langle\mathrm{c}+\mathrm{a}\rangle$ dislocations have been observed in 2 grains out of 12 grains studied. The lack of $\langle\mathrm{c}+\mathrm{a}\rangle$ dislocation is shown in Figure 6(b) by using the diffraction vector $g=0002$. On the other hand the presence of $\langle\mathrm{c}+\mathrm{a}\rangle$ dislocations is clearly observed in Figure 8(b) at low magnification and in Figure 9 at high magnification. As previously, the presence (filled triangle) or The absence (empty circle) of $\langle c+a\rangle$ dislocation is indicated on a (0002) pole figure for each grain studied (Figure 18). On this pole figure, the maximum $\langle c+a\rangle$-pyramidal Schmid factor for 240 orientations is also given in gray scale. Despite the high maximum $\langle c+a\rangle$-pyramidal Schmid factor computed for many of these grains, $\langle c+a\rangle$ glide occurs only in two grains, demonstrating again the high magnitude of the critical resolved shear stress of this slip system. It can also been noticed Figure 18, that the orientations of the two grains where $\langle c+a\rangle$ glide occurs are very different from the orientations of the other grains. Indeed, for these two grains the $\langle c\rangle$ axis is close to the transverse direction (referred as $\theta$ Figure 18).

The $\beta$ - Nb needles parallel to the basal plane are also observed (Figure 9) gathered in some sort of walls, as described in Reference 23.

In addition to these results, it can be noticed that prismatic channeling has never been observed for all of these grains. A grain well orientated to observe prismatic channel, with electron beam close to the $\underline{B} \approx[0002]$ direction and imaged in two-beam condition with diffraction vector $g=10 \overline{10}$ is shown in Figure 10 . No prismatic channel is observed in this grain. This shows that the prismatic critical resolved shear stress (CRSS) is high after irradiation. Nevertheless, for this loading condition, the maximum prismatic Schmid 


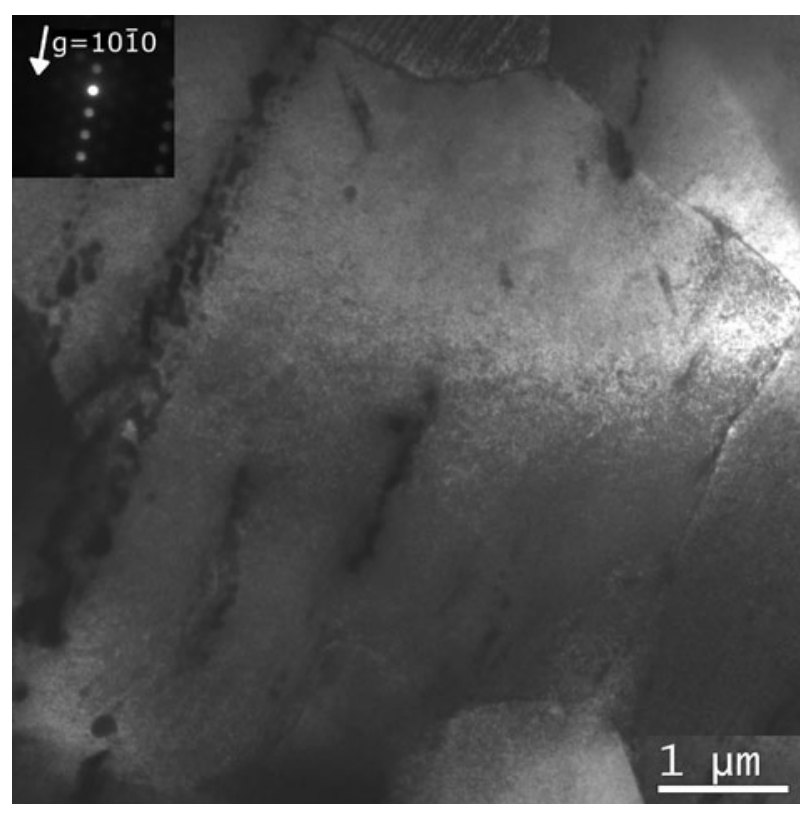

Fig. 10 - Grain 18 of specimen \#2 observed close to the zone axis $\underline{B} \approx[0002]$ with a $\underline{g}=10 \overline{10}$ diffraction vector. No prismatic channel is observed.

factor is always below 0.3 , as shown Figure 16, also explaining the more difficult activation of this system.

These results are in good agreement with the TEM observations reported in Reference 9 where 43 grains contained basal channels out of 80 grains studied for IP tests, but no prismatic channel was observed.

\section{DISCUSSION ON TEM OBSERVATIONS}

First, $\langle\mathrm{a}\rangle$ dislocations have been observed at high magnification for specimen \#1 in a wide channel (Figure 3). As discussed previously, these dislocations are believed to be mainly screw, deduced from the orientation of the dislocation and the orientation of the easy basal slip system. Furthermore, no dislocation is observed inside the channels for specimen \#2. This is consistent with the assumed screw character of dislocations present in the channels. Indeed, due to the strong texture of the material, when the thin foil is taken in the RD-TD plane (Radial Direction-Transverse Direction or $\theta-z$ ), the maximum shear stress direction (close to the activated Burgers vector) is not contained in the thin foil. Therefore, the screw dislocations cannot be correctly observed as shown schematically in Figure 4. The fact that mainly screw dislocations are observed within the channel is in good agreement with the mechanism for dislocation channeling proposed by Nogaret et al. ${ }^{[24,25]}$ By using molecular dynamic computation and dislocation dynamic simulations, these authors have shown that wavy and heavily jogged screw dislocations are present in the cleared band. Indeed, screw dislocations are strongly pinned by the helix turns formed by the absorption of loops as shown in References 10, 24, and 25. It can also be noticed in Figure 3 that the wavy screw dislocations are mainly observed at channel walls.
According to Reference 25, the progressive clearing and broadening of the channel occurs by successive absorption of loops within the jogged dislocation, leaving heavily jogged screw dislocations on its wake, at the edge of the channel. The screw segments shown in Figure 4 then define the limits of the edge part of the dislocation.

The fact that dislocation channels, when observed from two perpendicular points of view, and with the electron beam in the basal plane, appear as clear bands going all across the grains prove that they consist, in 3 dimensions, of thin slices parallel to the basal planes. Furthermore, when observed with the electron beam along the $\langle\mathrm{c}\rangle$ axis, no channel is observed. These observations can only be explained by considering that clearing of loops is due to dislocations gliding in the basal plane.

It is also believed, according to References 25 , and 26 that at the tip of the channel, on the grain boundary, dislocation pile-up is created. Indeed, as discussed in References 20, and 21, the strong localization of the plastic strain within the channel must induce high stress concentration at the tip of the channel, on the grain boundary. The grain boundary, in return, induces back stress. For high stress concentration, it is believed that a dislocation source is activated in the neighbouring grain, leading to the propagation of the channel from grain to grain. Furthermore, this phenomenon is enhanced by the strong texture of the material. The propagation of channels is clearly observed for specimen \#1, as shown in Figure 2. On the other hand, this phenomenon has never been observed for specimen \#2. This can be explained by the fact that the propagation of channels from grain to grain occurs in the shearing direction. Indeed, as the material exhibits a strong texture $(\langle c\rangle$ axis in the ND-TD plane as shown in Figure 1), for TT test, the best orientation for the shearing direction in the basal plane is contained in the ND-TD plane and is tilted at $45 \mathrm{deg}$ from ND. Therefore, the propagation of channels from grain to grain is best observed in thin foils taken in the ND-TD plane (Figure 4). On the contrary, for the thin foil taken in the RD-TD plane (or $z-\theta$ plane, in the case of cladding tube), the propagation of channels is not be observed in agreement with the TEM observations for specimen \#2. The propagation of channels from grain to grain is a very important mechanism as it allows the plastic accommodation of the strong stress concentration arising at the tip of the channels.

Furthermore, in some cases, deviation of basal channels out of the basal plane, in the pyramidal plane, has also been observed (Figure 7). This deviation is probably due to $\langle\mathrm{a}\rangle$ screw dislocations gliding in the basal plane that cross-slip in the first-order pyramidal plane. Indeed, for non-irradiated material, $\langle a\rangle$-pyramidal slip is often considered as a cross slip glide system for $\langle a\rangle$ screw dislocations gliding in prismatic plane. The same phenomenon is believed to occur after irradiation for the basal slip system.

The TEM analysis has also been able to show the presence of dislocations with $\langle\mathrm{c}+\mathrm{a}\rangle$ Burgers vector in the specimen \#2, probably gliding in the first-order pyramidal plane through the high density of $\langle a\rangle$ loops. 
This can be explained by the fact that the grains that are not well orientated for the slip in the $\langle a\rangle$ direction undergo a very high local stress. Therefore, in order to accommodate the high stress, first-order pyramidal slip with $\langle\mathrm{c}+\mathrm{a}\rangle$ Burgers vector occurs.

TEM analysis also revealed that prismatic channeling does not occur in these two specimens whereas before irradiation prismatic slip is the easy glide system. The change of easy slip system is believed to be due to differences in elementary interactions between dislocation and loops as discussed in detail in References 9, and 10. Indeed, the junction created between the $\langle\mathrm{a}\rangle$ dislocation gliding in the basal plane and $\langle a\rangle$ loops can always glide in the basal plane as it possesses another $\langle a\rangle$ Burgers vector which also belongs to the basal plane. In that case the dislocation can easily sweep up the loops, leading to an easy clearing and thus to an easy dislocation glide. Furthermore the glide cylinder of all three variants of $\langle a\rangle$-type loops are along the basal plane explaining the easy sweeping of all loops for this slip system. On the other hand, the junction created between the $\langle$ a $\rangle$ dislocation gliding in the prismatic plane and a 〈a loop with a different Burgers vector possesses another $\langle a\rangle$ Burgers vector that does not belong to the gliding plane of the dislocation. The junction therefore acts as obstacle against the dislocation glide, and the loop clearing is more difficult in that case. It is nevertheless worth noticing that when basal slip is not well orientated for glide, as in the case of axial tensile tests, significant prismatic glide occurs ${ }^{[9,20]}$ leading to the creation of channels in the prismatic plane. In the case of the two specimens presented here (TT test and IP test), it is possible that in some grains, limited prismatic slip occurs that does not lead to loop clearing.

\section{POLYCRYSTALLINE MODELING}

The slip system activities deduced from TEM observations in many grains presented here constitutes a rich data base which can be compared with polycrystalline models at the microscopic scale in addition to the usual fitting on the macroscopic mechanical behavior. In the following, the polycrystalline model developed is presented, and the simulations are compared with TEM observations.

\section{A. Basics on Polycrystalline Modeling}

As reviewed by many authors ${ }^{[27-30]}$ polycrystalline models, based on the so-called "self-consistent scheme", are able to evaluate the effective properties of a polycrystalline aggregate from the knowledge of the behavior of its constituents. In the self-consistent framework, the geometry of the grain aggregate is not taken into account. All the grains with the same crystallographic orientation are considered as the same crystallographic phase (g) characterized by its three Euler's angles $\left(\phi_{1}, \varphi, \phi_{2}\right)$ only and its volume fraction $\left(f_{\mathrm{g}}\right)$. These data are obtained experimentally by X-ray diffraction texture analysis. A list of 240 different crystallographic orientations representative of the texture of the material is chosen here (Figure 11).

In this approach, each crystallographic phase of the polycrystal can be successively regarded as an inclusion within the "matrix" made of all the crystallographic phases (homogeneous equivalent medium) submitted to homogeneous boundary conditions (mean field approach). The behavior of the polycrystal is then calculated by some adequate average process over all crystallographic phases. Several approaches have been derived theoretically, as reviewed in References 27-30. The homogenization technique used here is a simplified approach. The various steps of the computation are described below.

First, the elastic behavior is considered to be isotropic in each grain leading to a homogeneous elastic behavior only characterized by the overall macroscopic Young's modulus $(E)$ and the Poisson's ratio $(v)$.

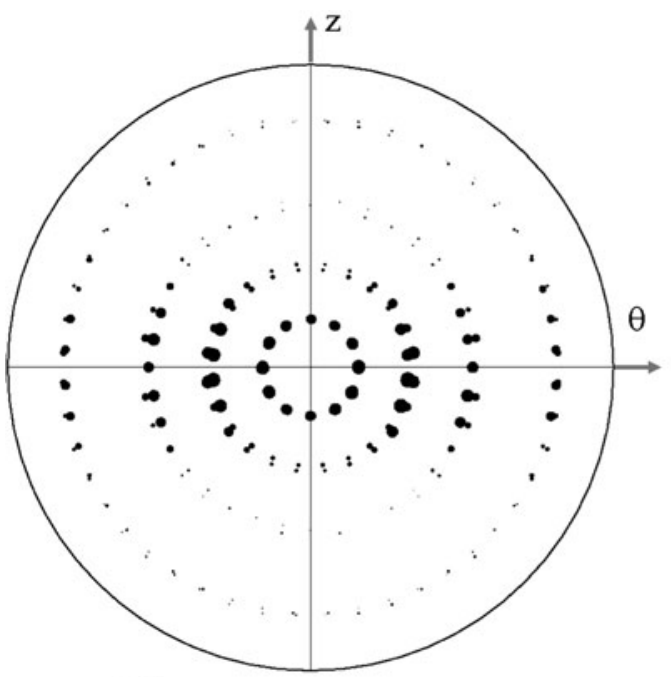

(a) (00.2) pole figure

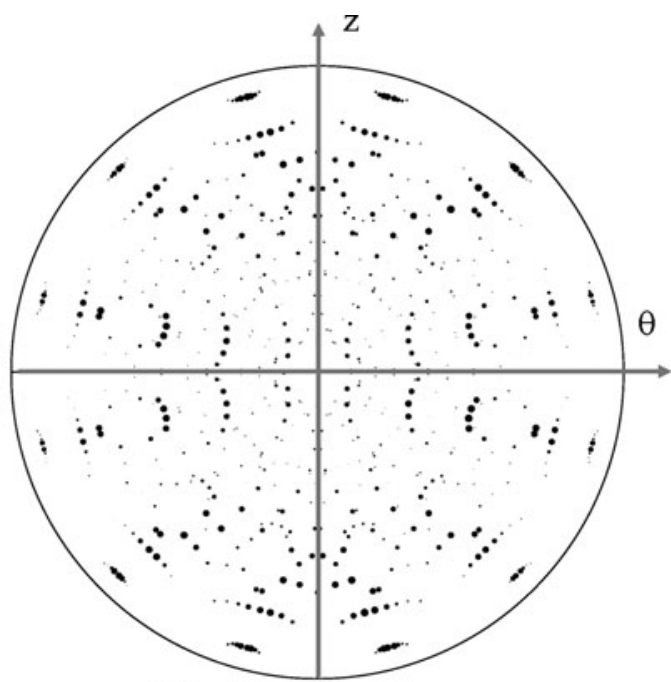

(b) $\{11.0\}$ pole figure

Fig. 11-Discrete pole figures of the set of 240 crystallographic orientations. 
From the knowledge of the loading (six components of either stress or strain tensors) and of the current macroscopic plastic strain $\left(E^{\mathrm{p}}\right)$ the macroscopic stress tensor $\Sigma$ is deduced from the generalized Hook's law (Eq. [3]).

$$
\underline{\underline{\Sigma}}=\sum_{\mathrm{g} \in G} f_{\mathrm{g}} \underline{\underline{\sigma}}_{\mathrm{g}}=2 \mu\left\{\mathbf{I}+\frac{v}{1-2 v} \underline{\underline{I}} \otimes \underline{\underline{I}}\right\}\left(\underline{\underline{E}}-\underline{\underline{E}}^{\mathrm{p}}\right)
$$

where $\mu=E /(2+2 v)$ is the shear modulus.

Then, the local stress $\left(\underline{\sigma}_{g}\right)$ in the considered crystallographic phase $(\mathrm{g})$ is computed thanks to the concentration rule relating the macroscopic stress $(\underline{\Sigma})$ to the local stress $\left(\underline{\sigma}_{g}\right)$ given by the homogenization method. Details concerning this method can be found in References 21, 31-34.

The resolved shear stress on each slip system (s) of the phase $(\mathrm{g})$ is then computed using Eq. [1]. Thanks to the intra-granular constitutive laws $\left(\dot{\gamma}_{\mathrm{s}}=f\left(\tau_{\mathrm{s}}, \ldots\right)\right)$, which takes into account the resolved shear stress as well as some internal variables, the shear strain rate $\left(\dot{\gamma}_{\mathrm{s}}\right)$ on each slip system of the phase $(\mathrm{g})$ is computed. Eventually, the plastic strain rate tensor of each crystallographic phase $\left(\dot{\underline{\varepsilon}}_{\mathrm{g}}^{\mathrm{p}}\right)$ is deduced according to Eq. [4].

$$
\dot{\underline{\varepsilon}}_{\mathrm{g}}^{\mathrm{p}}=\frac{1}{2} \sum_{\mathrm{s} \in S} \dot{\gamma}_{\mathrm{s}}\left(\underline{n}_{\mathrm{s}} \otimes \underline{m}_{\mathrm{s}}+\underline{m}_{\mathrm{s}} \otimes \underline{n}_{\mathrm{s}}\right)
$$

Finally, when this calculation has been done for every crystallographic phases $(\mathrm{g})$, the overall plastic strain rate can be computed as Eq. [5].

$$
\underline{\underline{E}}^{\mathrm{p}}=\sum_{\mathrm{g} \in G} f_{\mathrm{g}} \dot{\underline{\varepsilon}}_{\mathrm{g}}^{\mathrm{p}}
$$

A time integration algorithm is then used to compute the new values of all internal variables and all plastic shear strains.

In the following, the intra-granular constitutive laws proposed for neutron-irradiated recrystallized zirconium alloys, accounting for the dislocation channeling phenomenon, are presented. More details about this model can be found in Reference 21 .

\section{B. Intragranular Constitutive Laws}

\section{Deformation modes}

Four types of slip systems are taken into account in the model :

- the three prismatic slip systems,

- the three basal slip systems,

- the six first-order pyramidal slip systems with $\langle a\rangle$ Burgers vector,

- the twelve first-order pyramidal slip systems with $\langle\mathrm{c}+\mathrm{a}\rangle$ Burgers vector.

After irradiation, it has been shown that basal slip is the easy glide slip system. Some $\langle c+a\rangle$ dislocations have been observed also suggesting a probable activation of pyramidal $\langle c+a\rangle$ slip system. Prismatic and $\langle a\rangle$-pyramidal slips are also able to be slightly activated even if no prismatic, or pyramidal channel, has been observed.

\section{Irradiation-induced hardening}

The usual condition for activation of slip in system (s) of phase (g) is such that when $\left|\tau_{\mathrm{s}}\right|<\tau_{\mathrm{s}}^{\mathrm{c}}$ no slip occurs but when $\left|\tau_{\mathrm{s}}\right| \geq \tau_{\mathrm{s}}^{\mathrm{c}}$ slip occurs. The coefficient $\tau_{\mathrm{s}}^{\mathrm{c}}$ is the CRSS of the slip system (s). This CRSS is affected by irradiation.

Indeed, it is known that the radiation-induced loops act as obstacles against dislocation glide in the same way as forest dislocations. This therefore leads to an increase of the critical resolved shear stresses for all slip systems. According to the classical dispersed barrier hardening model $^{[35]}$ the increase of the critical resolved shear stress can be expressed as Eq. [6].

$$
\Delta \tau=\alpha \mu b \sqrt{N d}
$$

where $\mu$ is the shear modulus (in MPa), $N$ is the loop number density (in $\mathrm{m}^{-3}$ ), $d$ is the loop diameter (in $\mathrm{m}$ ), $b$ is the Burgers vector (in $\mathrm{m}$ ) and $\alpha$ is the proportionality factor characteristic of the strength of the obstacle.

In the case of recrystallized zirconium alloys irradiated in PWR conditions, it is shown that the loop density increases up to $N_{0}=5 \times 10^{22} \mathrm{~m}^{-3}$ with a mean loop diameter of $d=10 \mathrm{~nm}$ according to Régnard et $a l^{[19]}$ and seems to saturate for fluences above $5 \times$ $10^{25} \mathrm{~nm}^{-2}$. In the model, the values for $N_{0}$ and $d$ are kept fixed in the following and are chosen as $N_{0}=5 \times$ $10^{22} \mathrm{~m}^{-3}$ and $d=10 \mathrm{~nm}$.

Owing to the differences in the interaction between loops and dislocations gliding either in the basal plane or in other planes, the increase in the critical resolved shear stresses (CRSS) is believed to be different for each slip system. This can be taken into account by introducing different obstacle strength for each slip system. The irradiation-induced hardening is therefore modeled according to Eq. [7].

$$
\tau_{\mathrm{s}}^{\mathrm{c}}=\tau_{\mathrm{s}}^{\mathrm{c} 0}+\alpha_{\mathrm{s}} \mu b \sqrt{\rho_{1}} \quad \text { with } \rho_{1}=N d
$$

\section{Softening behavior at the grain scale}

Owing to the progressive cleaning of irradiation defects by basal channeling, softening occurs inside the channels. An intra-granular softening behavior is therefore introduced at the grain scale. As full clearing of loops occurs inside basal channels, only the basal CRSS is assumed to be affected by the strain softening, the other CRSS remaining constant with plastic strain (Eq. [8] and [9]) in a first approximation.

$\tau_{\mathrm{B}}^{\mathrm{c}}=\tau_{\mathrm{B}}^{\mathrm{c} 0}+\alpha_{\mathrm{B}} \mu b \sqrt{\rho_{1}}$ with $\rho_{l}=N d$, for basal slip systems

and

$$
\tau_{\mathrm{s}}^{\mathrm{c}}=\tau_{\mathrm{s}}^{\mathrm{c} 0} \text { for the other slip systems }
$$

with $\tau_{\mathrm{s}}^{\mathrm{c} 0}$ accounting for the radiation-induced hardening of the other slip systems. 
The clearing up process can be modeled, as proposed in References 36 , and 37 , by considering that all the loops lying within a given distance $(H / 2)$ to the dislocation plane (basal plane in this case) are captured and cleared up by the dislocation. Taking into account the dislocation density $\rho$ inside the channel gliding at the velocity $\bar{v}$, it is shown that during a time $d t$, the number of cleared loops inside the channel is $N H \rho \bar{v} d t$. From the Orowan equation $(\dot{\gamma}=\rho b \bar{v})$, the number of loops cleared up inside the channel during the time $d t$ can be expressed as $\frac{H}{b} N \dot{\gamma} d t$. Therefore, the equation governing the evolution of the loop linear density (or $\rho_{1}=N d$ ) can be deduced, written here (Eq. [10]) in a more general way by adding the contribution of all the dislocations gliding on the three basal slip systems $(s \in B)$.

$$
\frac{d \rho_{1}}{d t}=-k_{B} \rho_{1}\left[\sum_{\mathrm{s} \in \mathrm{B}}\left|\dot{\gamma}_{\mathrm{s}}\right|\right]
$$

with $\rho_{1}=N d, \rho_{1}(0)=N_{0} d, k_{\mathrm{B}}=H / b, N_{0}=5 \times 10^{22} \mathrm{~m}^{-3}$ and $d=10 \mathrm{~nm}$.

\section{Intragranular kinematic strain hardening}

As the dislocation channeling mechanism leads to strain localization, stress concentration arises at the tip of the channels thus inducing significant back stress. This additional back stress can be accounted for, at the intra-granular scale, by introducing a non-linear kinematic strain hardening term ${ }^{[29,38]}$, similar to the Armstrong-Frederick law, ${ }^{[39]}$ as shown in Eqs. [11] and [12]. The non-linear evolution of the kinematic strain hardening is needed as plastic accommodation occurs between the channel and the neighboring grains by channel propagation. Furthermore, as only basal channels are observed, the intra-granular kinematic hardening only affects the basal slip system. The intra-granular kinematic strain hardening is expressed as:

$$
\begin{aligned}
& \text { When }\left|\tau_{\mathrm{s}}-x_{\mathrm{s}}\right|<\tau_{\mathrm{s}}^{\mathrm{c}} \text {, then no slip occurs. } \\
& \text { When }\left|\tau_{\mathrm{s}}-x_{\mathrm{s}}\right| \geq \tau_{\mathrm{s}}^{\mathrm{c}} \text {, then slip occurs. }
\end{aligned}
$$

with $x_{\mathrm{s}}=0$ for non-basal slip systems $(\mathrm{s} \neq \mathrm{B})$

and $\dot{x}_{\mathrm{s}}=C_{\mathrm{B}} \dot{\gamma}_{\mathrm{s}}-D_{\mathrm{B}} x_{\mathrm{s}}\left|\dot{\gamma}_{\mathrm{s}}\right|$ for the basal slip systems

$$
(\mathrm{s} \in \mathrm{B}) \text {, with } x_{\mathrm{s}}(t=0)=0
$$

\section{Flow law}

A visco-plastic framework is chosen for the expression of the local constitutive behavior although the model is really suited for elasto-plastic behavior, as explained in Reference 21. The flow law expressed at the slip system scale is chosen as a power law given in Eq. [13]

$$
\dot{\gamma}_{\mathrm{s}}=\left\langle\frac{\left|\tau_{\mathrm{s}}-x_{\mathrm{s}}\right|-\tau_{\mathrm{s}}^{\mathrm{c}}}{K}\right\rangle^{n} \operatorname{sign}\left(\tau_{\mathrm{s}}-x_{\mathrm{s}}\right)
$$

The coefficients, $K$ and $n$, of the flow law (Eq. [13]) are chosen such that $K=5 \mathrm{MPa} . \mathrm{s}^{1 / \mathrm{n}}$ and $n=10$. With these coefficients, an increase of the applied strain rate from $10^{-6} \mathrm{~s}^{-1}$ up to $10^{-4} \mathrm{~s}^{-1}$ induces an increase of the flow stress at 0.2 pet plastic strain lower than $1 \mathrm{MPa}$, confirming that the chosen model is quasi elasto-plastic.

\section{Fitting and Validation of the Model Both at Macro and Microscopic Scales}

The model has been fitted on monotonic TT test and IP test performed at $623 \mathrm{~K}$. The simulated stress-strain curves are compared to the experimental results in Figure 12. The fitted coefficients of the polycrystalline model are given in Table III. The $D$ and $\delta$ coefficients come from the homogenization method described in Reference 21. The fitted CRSS values are equal to $240 \mathrm{MPa}$ for the prismatic and pyramidal $\langle\mathrm{a}\rangle$ slip and to $300 \mathrm{MPa}$ for the $\langle\mathrm{c}+\mathrm{a}\rangle$ pyramidal slip. As for the basal CRSS, it is equal to $188 \mathrm{MPa}$ at the onset of plastic flow and decreases progressively down to $90 \mathrm{MPa}$ after 15 pct of basal plastic shear strain, inside the grain.

The polycrystalline model has then been used to compute tension-compression cyclic tests (low cycle

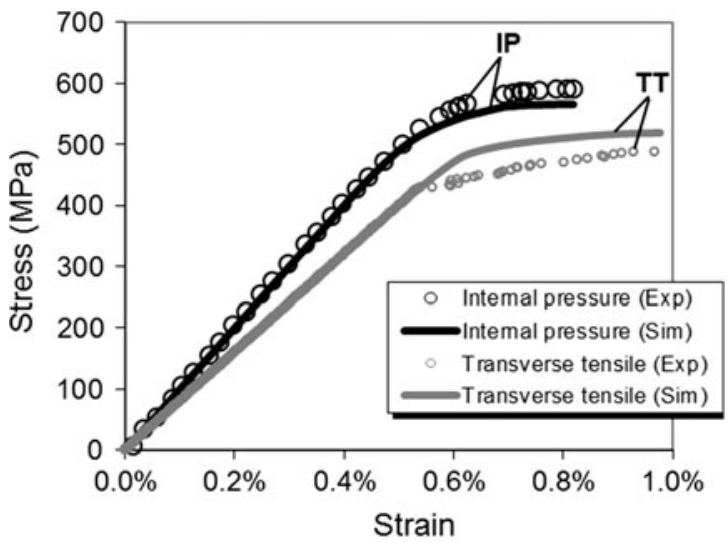

(a)

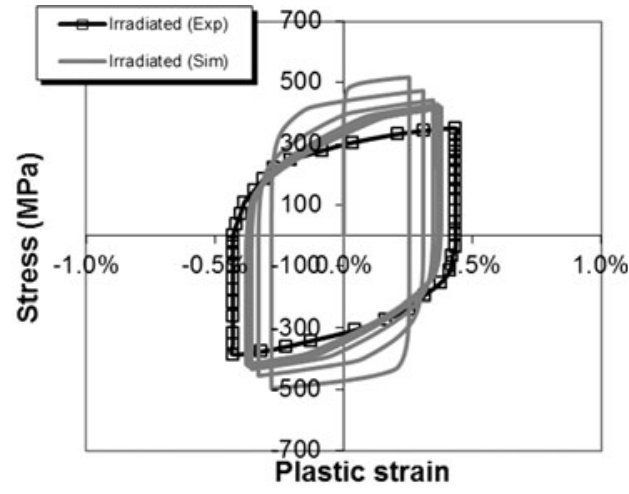

(b)

Fig. 12-(a) Experimental (Exp) and Simulated (Sim) stress-strain curves of the Transverse Tensile (TT) test and the Internal Pressure (IP) test for irradiated recrystallized zirconium alloys. (b) Simulation of low cycle fatigue test in the transverse direction and comparison with experimental stabilized hysteresis loop obtained in Ref. [40]. 
Table III. Coefficients of the Polycrystalline Model Adapted to the Irradiated Material

\begin{tabular}{ll}
\hline Parameter & Value \\
\hline$E^{*}(\mathrm{MPa})$ & 80,000 \\
$\nu^{*}$ & 0.4 \\
$n^{*}$ & 10 \\
$K^{*}\left(\mathrm{MPa} \cdot \mathrm{s}^{1 / \mathrm{n}}\right)$ & 5 \\
$\tau_{P}^{c}(\mathrm{MPa})$ & 240 \\
$\tau_{\pi\langle a\rangle}^{c}(\mathrm{MPa})$ & 240 \\
$\tau_{\pi j c+a\rangle}^{c}(\mathrm{MPa})$ & 300 \\
$\tau_{B}^{c 0}(\mathrm{MPa})$ & 85 \\
$\rho_{b}(0)^{*}\left(\mathrm{~m}^{-2}\right)$ & $5 \times 10^{14}$ \\
$\alpha_{\mathrm{B}}$ & 0.5 \\
$k_{\mathrm{B}}$ & 40 \\
$C_{\mathrm{B}}(\mathrm{MPa})$ & $1 \times 10^{5}$ \\
$D_{\mathrm{B}}$ & 3000 \\
$D$ & 280 \\
$\delta$ & 0.53 \\
\hline
\end{tabular}

*Fixed coefficients.

fatigue) performed at $623 \mathrm{~K}\left(350{ }^{\circ} \mathrm{C}\right)$ in the transverse direction for neutron-irradiated recrystallized zirconium alloys. ${ }^{[40]}$ In Figure 12 the simulated stress-plastic strain curve obtained during low cycle fatigue test is shown and compared to the experimental stabilized hysteresis loop. The strong Bauschinger effect observed on the experimental stabilized hysteresis loop is very well reproduced by the model. Furthermore, a cyclic strain softening is computed by the model which is also in good agreement with the results obtained by Wisner et al. ${ }^{[40]}$ This computation therefore validates the model at the macroscopic scale.

Furthermore, at the microscopic scale, the polycrystalline model has been compared to TEM observations. Indeed, for each grain studied by TEM, the crystallographic orientation of the grain, with respect to the macroscopic frame, is known. The three Euler's angles $\left(\phi_{1}, \varphi, \phi_{2}\right)$ of each grain studied by TEM are added to the list of 240 crystallographic orientations representative of the texture, but a very low volume fraction $\left(f_{\mathrm{g}}\right)$ is attributed to these grains not to disturb the macroscopic response of the polycrystal. The mechanical tests are then simulated, and all along the tests the sum of the shear strain rate on each slip system family of these grains is computed. The basal shear strain rate, for instance, is computed as Eq. [14].

$$
\dot{\gamma}_{B}=\sum_{s \in B}\left|\dot{\gamma}_{s}\right|
$$

During the simulation, the shear strain rates evolve quickly at the beginning, but a steady state is rapidly reached. The shear strain rates of each slip system family at the last step of the test, representative of the steady state, are computed for the 240 crystallographic orientations. The values are plotted in gray scale in Figures 13(b) through 18(b). On these plots are also shown the results of TEM observations. As previously, the presence of basal channels or $\langle c+a\rangle$ dislocations is shown as filled triangle, and the absence of basal channel, $\langle\mathrm{c}+\mathrm{a}\rangle$ dislocation, and prismatic channel is shown as empty circle. The shear strain rates have also been computed for the grains studied by TEM allowing a more accurate comparison between simulations and experiments (Figures 13 through 18). The disagreements between the computed shear strain rates, and TEM observations are underlined Figures 13(b) through 18(b) using a large empty circle.

\section{Discussion on the Comparison Between the Polycrystalline Model and TEM Observations}

First, it can be seen that there is a close correlation between the shear strain rates and the Schmid factors. Indeed, the model follows the trend shown by the Schmid factors but introduces a threshold in the pattern drawn on the pole figure.

Second, it can be noticed that for TT test (specimen $\# 1$ ), there is a very good agreement between shear strain rates in the grains and TEM observations. Only for two grains, the prismatic slip system is significantly activated but no prismatic channel was observed.

In the case of IP test (specimen \#2), the agreement is also very good. Only in three grains the model predicts a significant activation of the basal slip but no basal channel was observed. This disagreement could come from the assumption that all the grains with the same crystallographic orientation undergo the same stress. In fact, in a polycrystal, it is well known ${ }^{[29,30]}$ that there are strong stress heterogeneities and especially between grains with the same crystallographic orientation. Indeed, the neighbouring grains have a major impact on the magnitude of the local stress, explaining therefore the discrepancies observed.

In two grains, the model also predicts the activation of $\langle\mathrm{c}+\mathrm{a}\rangle$ pyramidal slip but no $\langle\mathrm{c}+\mathrm{a}\rangle$ dislocation was observed in these grains. Most remarkably, in the two grains where $\langle\mathrm{c}+\mathrm{a}\rangle$ dislocations were observed, the model predicts the activation of $\langle c+a\rangle$ pyramidal slip. The disagreements concerning the $\langle\mathrm{c}+\mathrm{a}\rangle$ pyramidal slip can come, as mentioned before, from the effect of the neighbouring grains that induce a different local stress in grains with the same crystallographic orientation. Moreover, it is believed that $\langle\mathrm{c}+\mathrm{a}\rangle$ glide only arise at strong stress concentration points inside the grain. The distribution of $\langle\mathrm{c}+\mathrm{a}\rangle$ dislocations inside the grain is therefore believed to be strongly heterogeneous. When preparing the TEM thin foil, only a very thin slice of grain is cut (100 $\mathrm{nm}$ out of $10 \mu \mathrm{m}$ grain diameter), and therefore some $\langle\mathrm{c}+\mathrm{a}\rangle$ dislocations present in the grain might not be observed by TEM.

To conclude the model gives correct predictions for 65 out of 72 different cases studied. That is to say, the model predicts more than 90 pct cases correctly. This thorough comparison between simulation and experiment gives a validation of the model at the microscopic scale in addition to the validation at the macroscopic scale, proving the good reliability of this modeling for irradiated $\mathrm{Zr}$ alloys. 


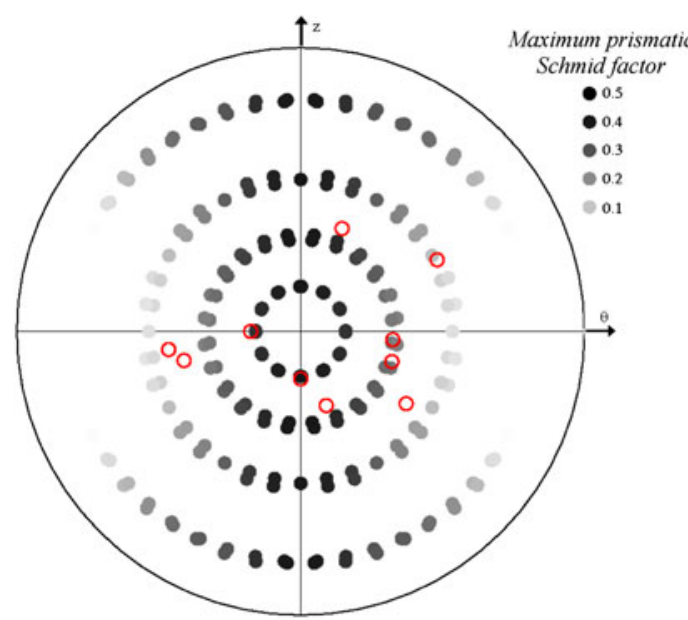

(a) (00.2) pole figure

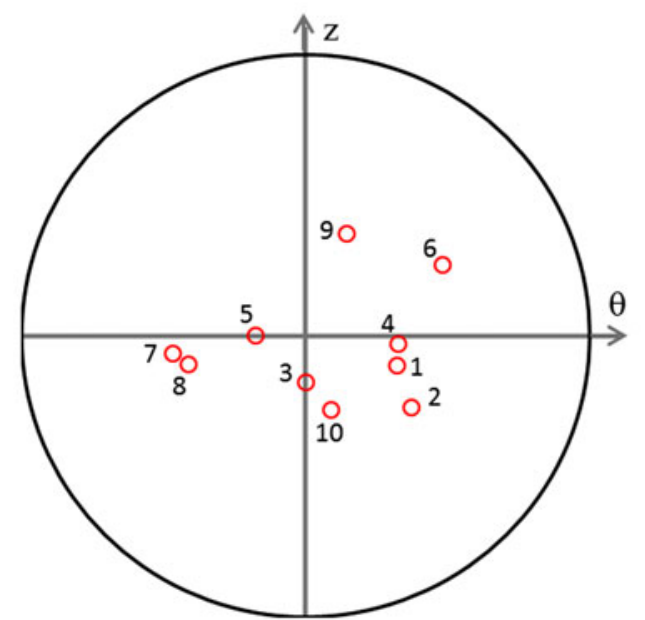

(c)

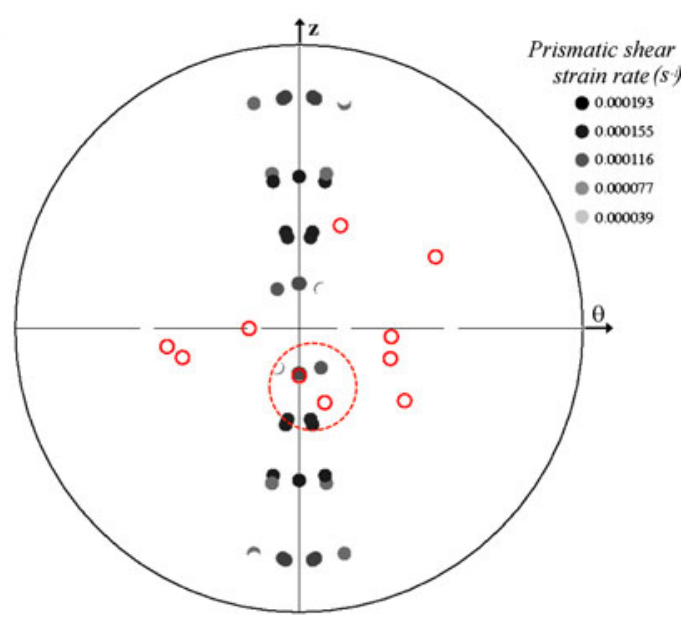

(b) (00.2) pole figure

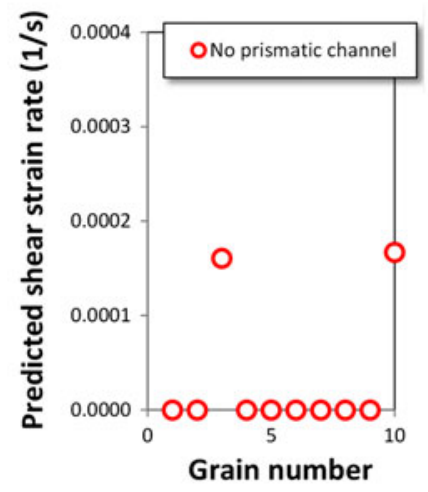

(d)

Fig. 13-Specimen \#1. (a) Maximum prismatic Schmid factors. (b) and (d) Prismatic shear strain rate. (c) Grains studied in specimen \#1 indicated on the (0002) pole figure with their number. The absence of prismatic channel is shown by empty circle. Disagreements between model and experiment are underlined by large circles.

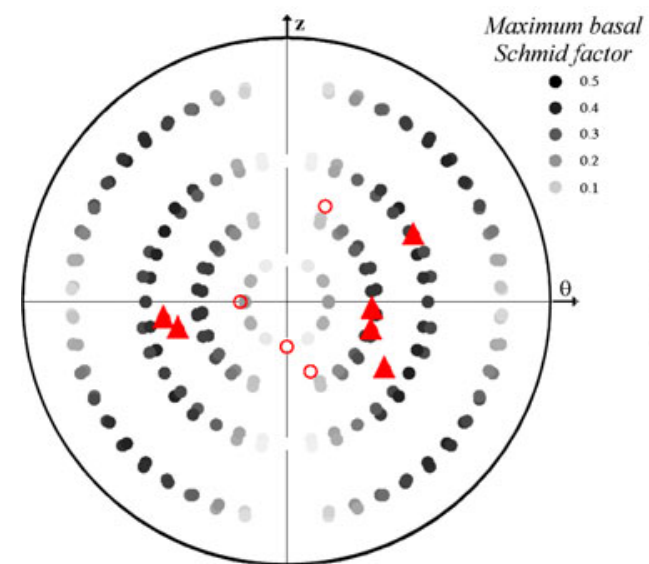

(a) (00.2) pole figure

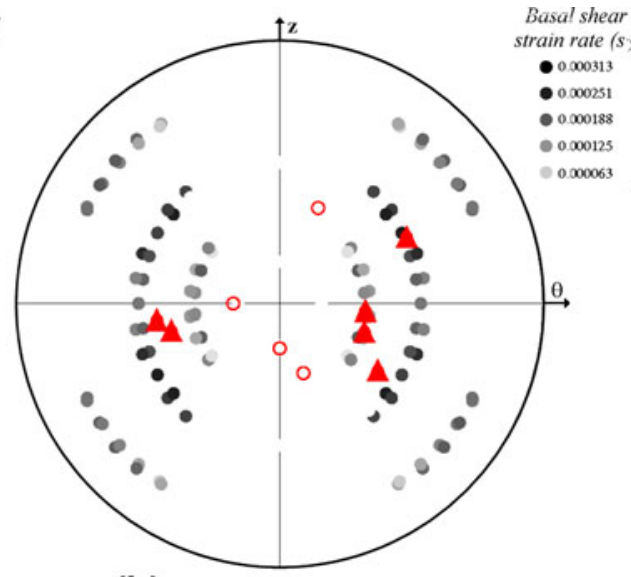

(b) (00.2) pole figure

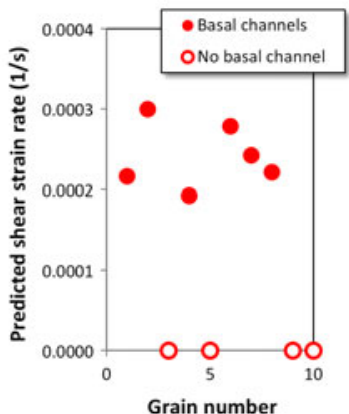

(c)

Fig. 14 -Specimen \#1. (a) Maximum basal Schmid factors. (b) and (c) Basal shear strain rate. The presence of basal channels is shown by filled triangle or filled circle. The absence of basal channel is shown by empty circle. 


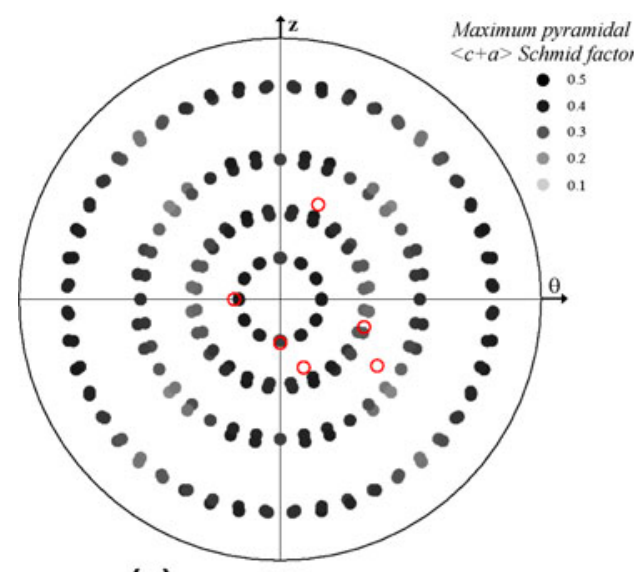

(a) (00.2) pole figure

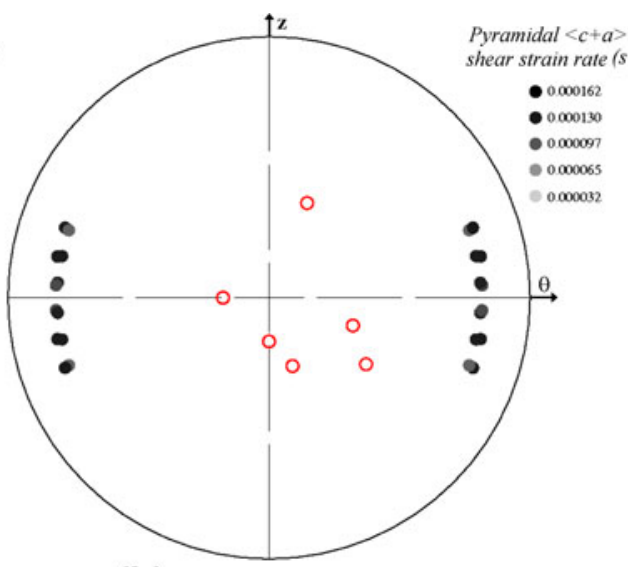

(b) (00.2) pole figure

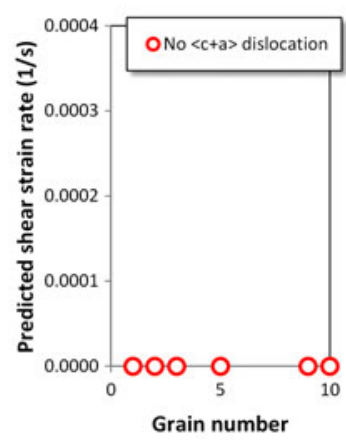

(c)

Fig. 15-Specimen \#1. (a) Maximum pyramidal $\langle\mathrm{c}+\mathrm{a}\rangle$ Schmid factors. (b) and (c) Pyramidal $\langle\mathrm{c}+\mathrm{a}\rangle$ shear strain rate. The absence of $\langle\mathrm{c}+\mathrm{a}\rangle$ dislocation is shown by empty circle.

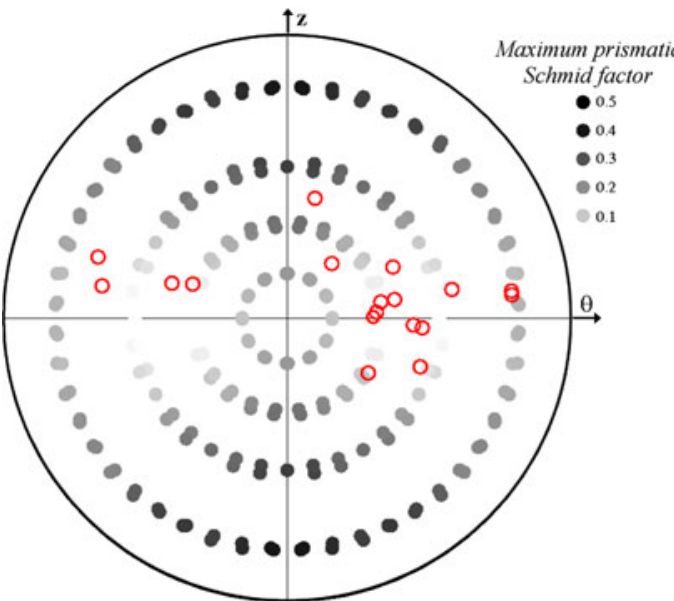

(a) (00.2) pole figure

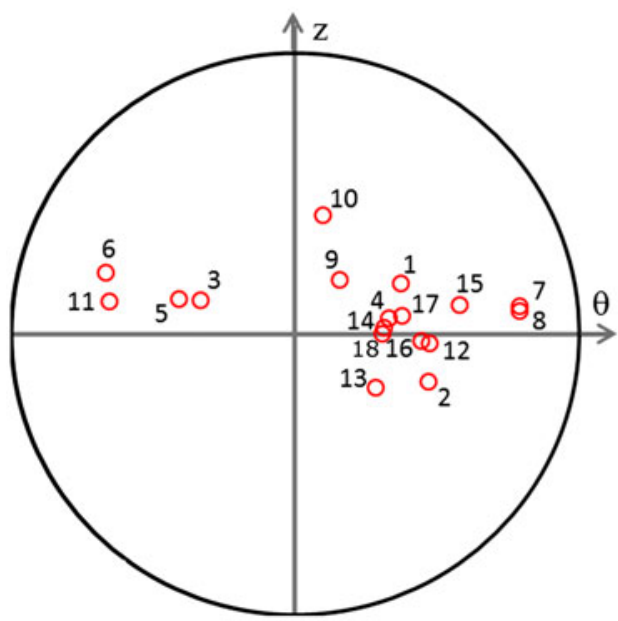

(c)

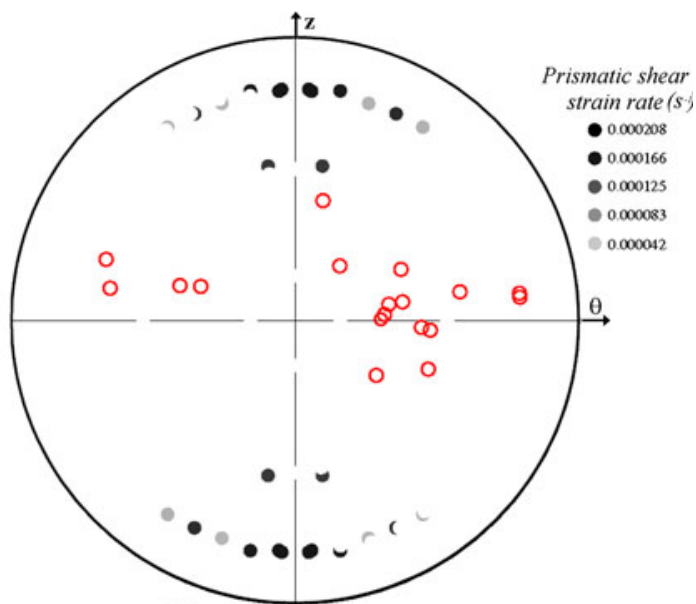

(b) (00.2) pole figure

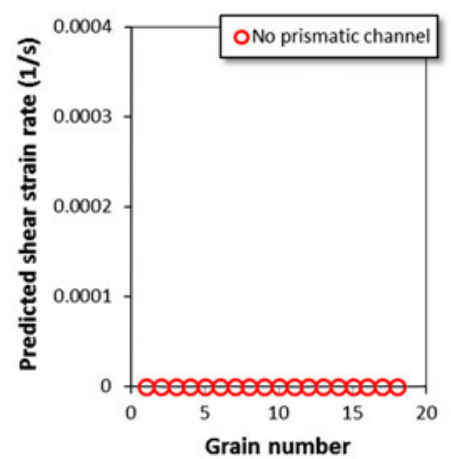

(d)

Fig. 16- Specimen \#2. (a) Maximum prismatic Schmid factors. (b) and (d) Prismatic shear strain rate. (c) Grains studied in specimen \#2 indicated on the (0002) pole figure with their number. The absence of prismatic channel is shown by empty circle. 


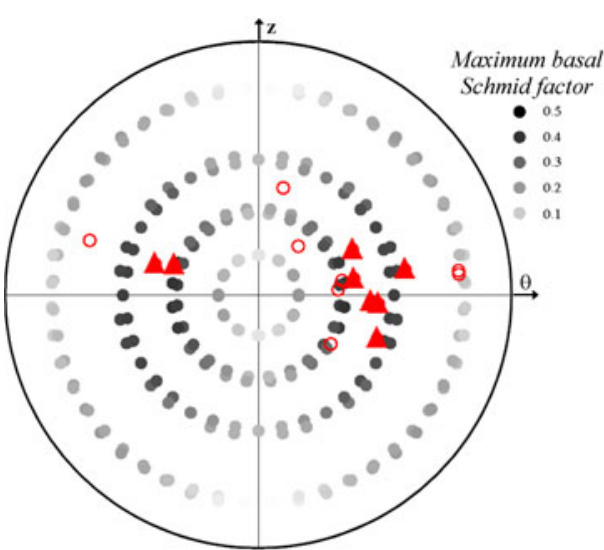

(a) (00.2) pole figure

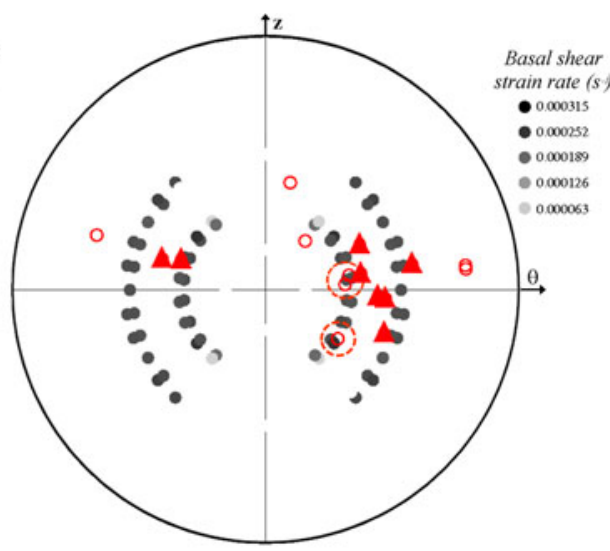

(b) (00.2) pole figure

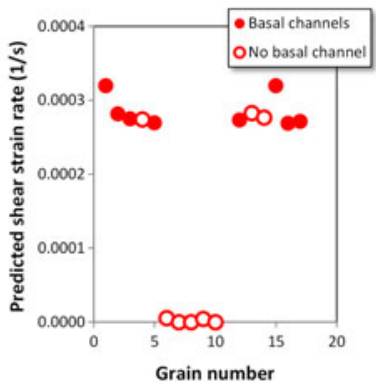

(c)

Fig. 17-Specimen \#2. (a) Maximum basal Schmid factors. (b) and (c) Basal shear strain rate. The presence of basal channels is shown by filled triangle or filled circle. The absence of basal channel is shown by empty circle. Disagreements between model and experiment are underlined by large circles.

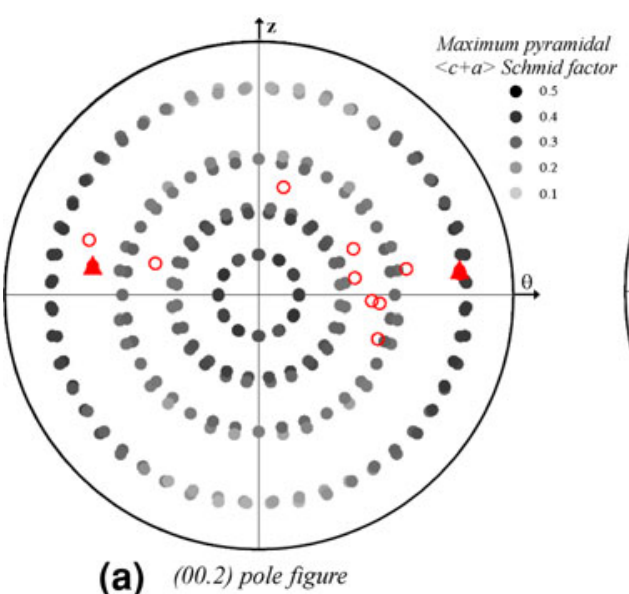

(a) (00.2) pole figure

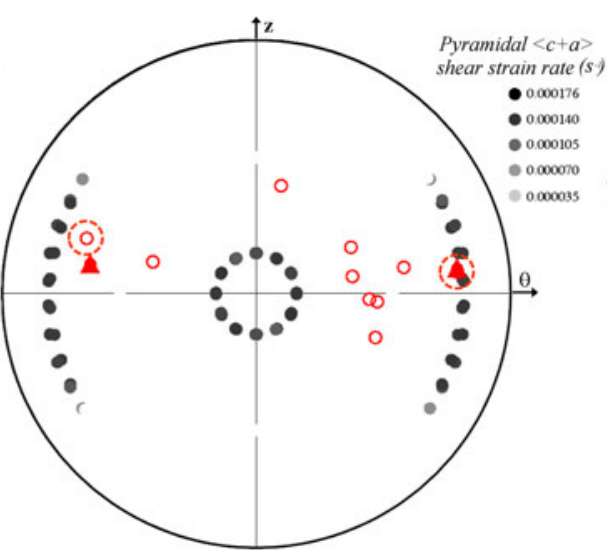

(b) (00.2) pole figure

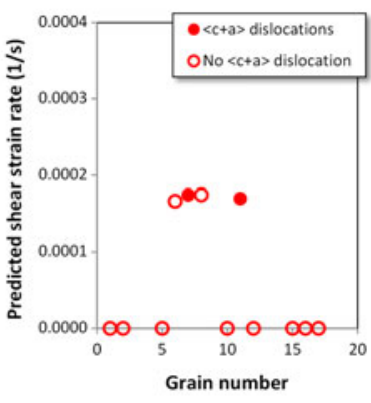

(c)

Fig. 18-Specimen \#2. (a) Maximum pyramidal $\langle\mathrm{c}+\mathrm{a}\rangle$ Schmid factors. (b) and (c) Pyramidal $\langle\mathrm{c}+\mathrm{a}\rangle$ shear strain rate. The presence of $\langle\mathrm{c}+\mathrm{a}\rangle$ dislocations is shown by filled triangle or filled circle. The absence of $\langle c+a\rangle$ dislocation is shown by empty circle. Disagreements between model and experiment are underlined by large circles.

\section{CONCLUSIONS}

The TEM analyses performed on several grains of two neutron-irradiated recrystallized zirconium alloys tested in TT test and IP test at $623 \mathrm{~K}\left(350^{\circ} \mathrm{C}\right)$, have shown that mainly basal slip is activated, which is in good agreement with previous studies. ${ }^{[9,20]}$ Furthermore, it is shown that basal glide occurs mainly via dislocation channeling. Some deviation of channels in the pyramidal plane has also been noticed. No prismatic channel has been observed for these two loading conditions. In addition, $\langle\mathrm{c}+\mathrm{a}\rangle$ pyramidal slip has been studied, and no $\langle\mathrm{c}+\mathrm{a}\rangle$ dislocation has been observed after TT test, whereas after IP test $\langle\mathrm{c}+\mathrm{a}\rangle$ dislocations are observed.

As the crystallographic orientations for all the grains studied are known, the TEM observations have been compared to slip system activities computed by a polycrystalline model adapted to irradiated recrystallized zirconium alloys. The developed polycrystalline model takes into account the irradiation-induced hardening due to loops, the strain softening due to the clearing of loops, as well as an intragranular kinematic strain hardening that accounts for the strain incompatibilities arising at the tip of the channels.

This model gives a very good prediction of the macroscopic behavior. Most remarkably, the strong Bauschinger effect and the cyclic strain softening are well predicted, although the model was only fitted on monotonic tests.

Furthermore, when comparing the activated slip systems computed by the model and the TEM observations, it is seen that the model gives more than 90 pct good predictions.

Improvement of the modeling can still be obtained by using more advanced homogenization techniques, ${ }^{[30,41,42]}$ by introducing the prismatic channeling which is observed only for axial tensile tests, ${ }^{[9]}$ or by using other experimental techniques such as neutron or synchrotron diffraction experiments. ${ }^{[43,44]}$

\section{ACKNOWLEDGMENTS}

The authors acknowledge the support provided for this study by EDF and AREVA. The authors are also 
grateful to A. Ambard for the latter's careful reading of the manuscript.

\section{REFERENCES}

1. D.L. Douglass: The Metallurgy of Zirconium. Atomic Energy Review Supplement, p. 41, International Atomic Energy Agency, Vienna, 1971

2. E. Tenckhoff: Deformation Mechanisms, Texture, and Anisotropy in Zirconium and Zircaloy, ASTM STP 966, American Society for Testing and Materials, West Conshohocken, PA, 1988.

3. F. Ferrer, A. Barbu, T. Bretheau, J. Crépin, F. Willaime, and D. Charquet: Zirconium in Nuclear Industry, 13th International Symposium, ASTM STP 1423, G.D. Moan and P. Rudling, eds., American Society for Testing Materials, West Conshohocken, PA, 2002 , p. 863.

4. R. Brenner, J.L. Béchade, O. Castelnau, and B. Bacroix: J. Nucl. Mater., 2002, vol. 305, p. 175.

5. D.O. Northwood: Atom. Energy Rev., 1977, vol. 15, pp. 547-610.

6. D.O. Northwood, R.W Gilbert, L.E. Bahen, P.M. Kelly, R.G. Blake, A. Jostsons, P.K. Madden, D. Faulkner, W. Bell, and R.B. Adamson: J. Nucl. Mater., 1979, vol. 79, pp. 379-94.

7. M., Griffiths: J. Nucl. Mater., 1988, vol. 159, pp. 190-218.

8. F. Onimus and J.L. Béchade: Comprehensive Nuclear Materials, R. Konings ed., vol. 4, pp. 1-31, Elsevier Ltd., Oxford, 2012.

9. F. Onimus, I. Monnet, and J.L. Béchade: J. Nucl. Mater., 2004, vol. 328 , pp. 165-79.

10. F. Onimus, L. Dupuy, and F. Mompiou: Prog. Nucl. Energy, 2012, vol. 57 , pp. $77-85$.

11. M.S. Wechsler: The Inhomogeneity of Plastic Deformation, ASM, Metals Park, OH, 1973, pp. 19-52.

12. A. Luft: Prog. Mater. Sci., 1991, vol. 35, pp. 97-204.

13. C.E. Coleman, D. Mills, and J. van der Kuur: Can. Metall. Q., 1972, vol. 11, pp. 91-100.

14. C.D. Williams, R.B. Adamson, and K.D. Olhausen: European Conference on Irradiation Behavior of Fuel Cladding and Core Component Materials, Gesellschaft für Kernforschung mbH., Karlsruhe, Germany, 1974, pp. 189-92.

15. T. Onchi, H. Kayano, and Y. Higashiguchi: J. Nucl. Mater., 1980, vol. 88, pp. 226-35.

16. K. Pettersson: J. Nucl. Mater., 1982, vol. 105, pp. 341-44.

17. R.B. Adamson and W.L. Bell: Microstructure and Mechanical Behavior of Materials, Proceedings, International Symposiums, vol. 1, pp. 237-246, EMAS, Warley, U.K., Xian, China, 1986.

18. M. Fregonese, C. Régnard, L. Rouillon, T. Magnin, F. Lefebvre, and C. Lemaignan: Zirconium in Nuclear Industry: Twelfth International Symposium, ASTM STP 1354, G.P. Sabol and G.D. Moan, eds., American Society for Testing Materials, West Conshohocken, PA, 2000, pp. 377-98.

19. C. Régnard, B. Verhaeghe, F. Lefebvre-Joud, and C. Lemaignan, Zirconium in the Nuclear Industry, 13th International Symposium, ASTM STP 1423, G.D. Moan and P. Rudling, eds., American Society for Testing Materials, West Conshohocken, PA, 2002, pp. 384-99.
20. F. Onimus, J.L. Béchade, C. Prioul, P. Pilvin, I., Monnet, S. Doriot, B. Verhaeghe, D. Gilbon, L. Robert, L. Legras, and J.-P. Mardon: J. ASTM Int., 2005, vol. 2, pp. 53-76.

21. F. Onimus and J.L. Béchade: J. Nucl. Mater., 2009, vol. 384, pp. 163-74.

22. D. Gilbon, A. Soniak, S. Doriot, and J.-P. Mardon: Zirconium in Nuclear Industry: Twelfth International Symposium, ASTM STP 1354, G.P. Sabol and G.D. Moan, eds., American Society for Testing Materials, West Conshohocken, PA, 2000, p. 51.

23. S. Doriot, D. Gilbon, J. L. Béchade, M.H. Mathon, L. Legras, and J. P. Mardon: J. ASTM Int., 2005, vol. 2, pp. 175-201.

24. T. Nogaret, C. Robertson, and D. Rodney: Philos. Mag., 2007, vol. 87, p. 945.

25. T. Nogaret, D. Rodney, M. Fivel, and C. Robertson: J. Nucl. Mater., 2008, vol. 380, pp. 22-29.

26. T.S. Byun and N. Hashimoto: J. Nucl. Mater., 2006, vol. 354, p. 123.

27. M. Berveiller and A. Zaoui: J. Mech. Phys. Solids, 1979, vol. 26, p. 325 .

28. U.F. Kocks, C.N. Tomé, and H.-R. Wenk: Texture and Anisotropy, Preferred Orientations in Polycrystals and Their Effect on Materials Properties, 1st ed., Cambridge University Press, Cambridge, 1998 .

29. F Barbe, L Decker, D Jeulin, and G Cailletaud: Int. J. Plast., 2001, vol. 17 , p. 513.

30. R. Brenner, R. Masson, O. Castelnau, and A. Zaoui: Eur. J. Mech. A/Solids, 2002, vol. 21, p. 943.

31. G. Cailletaud: Int. J. Plast, 1992, vol. 8, p. 55.

32. P. Pilvin: Proceedings of the International Conference on Biaxial/ Multiaxial Fatigue, pp. 31-46, ESIS/SF2M, Saint-Germain en Laye, 1994.

33. X. Feaugas, P. Pilvin, and M. Clavel: Acta Mater., 1997, vol. 45, pp. $2703-14$

34. M. Priser, M. Rautenberg, J.M. Cloué, P. Pilvin, X. Feaugas, and D. Poquillon: J. ASTM Int., 2011, vol. 8, pp. 10-19.

35. G.S. Was: Fundamentals of Radiation Materials Science, p. 594, Springer, Berlin, 2007.

36. D. Rodney, G. Martin, and Y. Bréchet: Mater. Sci. Eng. A, 2001, vols. 309-310, p. 198.

37. C. Pokor, X. Averty, Y. Bréchet, P. Dubuisson, and J.P. Massoud: Scripta Mater., 2004, vol. 50, p. 597.

38. L. Meric, P. Poubanne, and G. Cailletaud: J. Eng. Mater. Technol. (Trans. ASME), 1991, vol. 113, p. 162.

39. Y. Jiang and P. Kurath: Int. J. Plast., 1996, vol. 12, p. 387.

40. S.B. Wisner, M.B. Reynolds, and R.B. Adamson: Zirconium in the Nuclear Industry: 10th International Symposium, ASTM STP 1245, A.M. Garde and E.R. Bradley, eds., American Society for Testing Materials, West Conshohocken, PA, 1994, p. 499.

41. R. A. Lebensohn, C. N. Tomé, and P. Ponte Castañeda: Philos. Mag., 2007, vol. 87, pp. 4287-4322.

42. C. Mareau and M.R. Daymond: Acta Mater., 2010, vol. 58, pp. 3313-25.

43. N. Letouzé, R. Brenner, O. Castelnau, J.L. Béchade, and M.H. Mathon: Scripta Mater., 2002, vol. 47, p. 595.

44. F. Xu, R.A. Holt, and M.R. Daymond: J. Nucl. Mater., 2008, vol. 373 , pp. 217-25. 